\title{
Twenty Years of Study of the Etiology of Congenital Malformations in Finland
}

\author{
LAURI SAXÉN
}

\section{INTRODUCTION}

Not a single teratogenic factor has been detected in epidemiologic studies (Miller, 1975), and most associations demonstrated in such investigations have merely been confirmatory. Yet surveillance programs and special epidemiologic studies should be considered essential components of modern health care. They serve several functions: surveillance might detect trends and clusters in the incidence of malformations, which could lead to both preplanned analytical investigations and practical consequences (warnings). Furthermore, as nonepidemiologic, experimental methods suffer from serious drawbacks and limitations and their results cannot easily be extrapolated to human subjects (Fraser, 1964; Saxén and Rapola, 1969; Saxén, 1983), epidemiologic methods should be used in testing the hypotheses based on such experimental results.

This survey is basically a review of 20 years of experience with a national surveillance program and of the results of special studies based on that material. It deals with a restricted, ethnically uniform population. In addition to the advantages of a defined study population, the studies summarized here have profited from being performed by a single team of closely collaborating scientists. Hence, definitions, diagnostic measures, and handling of the material are uniform and the results of various studies are therefore comparable. On the other hand, the restricted target population and the inbred study group may entail serious limitations and fallacies: the population of 4.7 million is rather small for many types of investigations; the style of life of the people might include curiosities (e.g., the

LAURI SAXÉN • Department of Pathology, University of Helsinki, SF-00290 Helsinki 29, Finland. 
sauna) of minor global interest; and, finally, the team of investigators may have become narrow and prejudiced over the past 20 years of collaboration. Therefore, all observations and conclusions presented here should be reevaluated in other populations and perhaps by other approaches before generalizations can be made-not to mention institution of practical measures.

With these reservations in mind, the reader might be interested in this somewhat unusual approach and should also understand that it is not the author's intention to cover the voluminous literature of the field. Some key references are given, but otherwise the reader is referred to the original publications of the group containing the references to each particular problem.

\section{THE STUDY POPULATION}

Finland has a total area of $337,032 \mathrm{~km}^{2}$ and it lies between north latitudes $60^{\circ}$ and $70^{\circ}$ (Fig. 1A). The population of 4.7 million has remained remarkably stable over the past two decades, with some emigration (mainly to Sweden) but

A

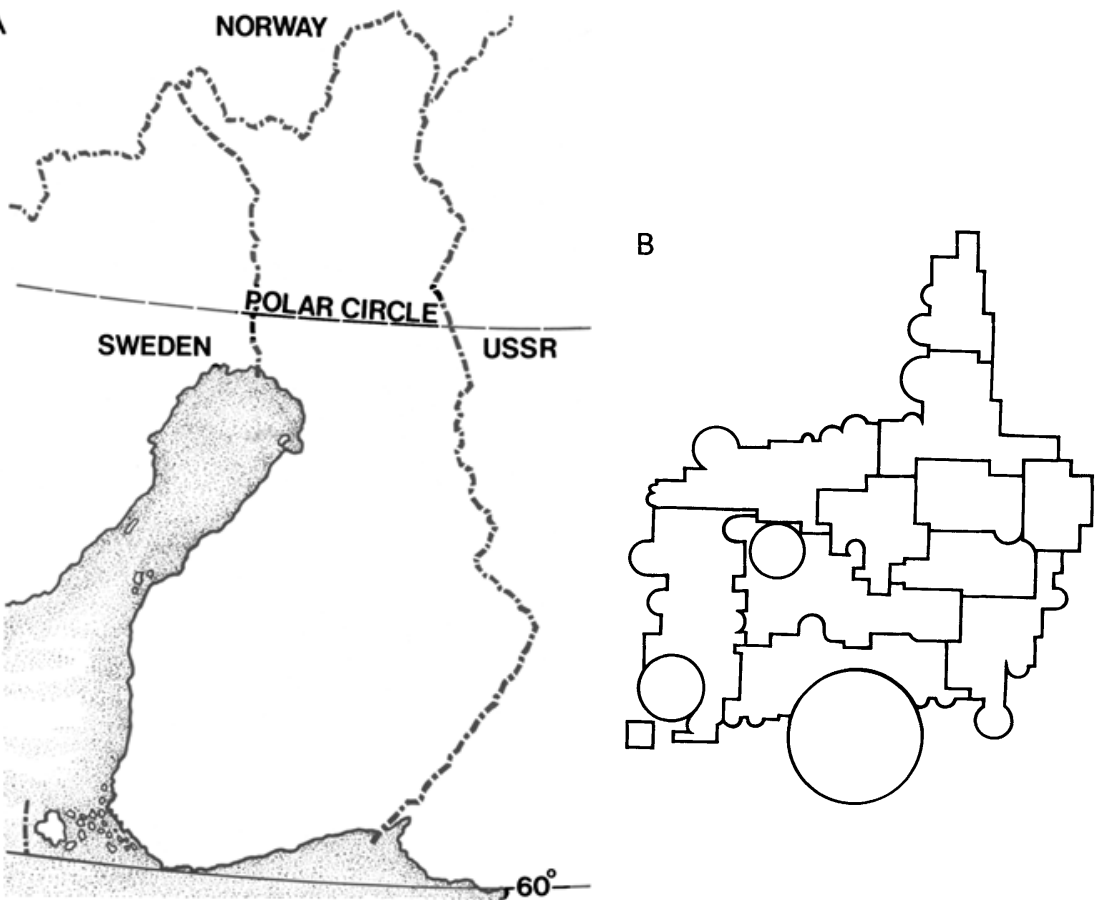

Figure 1. Map (A) and area cartogram (B) of Finland. In the latter the sizes of the areas and circles represent the relative size of the population in a region and major cities, respectively. 
little immigration. The population is Caucasoid, ethnically uniform, and includes elements of Scandinavian, Baltic, and Russian origin. Of the ethnic minorities, Lapps are the most distinct (total about 2000), and in addition there are very small Jewish and Gypsy minorities. The people belong to the Finno-Ugric language group, with a Swedish-speaking minority of $6 \%$. There is a definite concentration of population in the southern and western parts of the country (Fig. 1B), which are the most industrialized and prosperous districts. The urban/rural ratio has changed considerably over the past decades, due to internal migration to urban communities, and also because of administrative measures that have led to the establishment of numerous new towns. In 1950 the urban/rural ratio was approximately $1: 2$, while in 1975 the ratio was reversed. In the southernmost part, including the capital, Helsinki (population 500,000), the ratio is 10:1.

After the second World War an economic revolution took place in Finland. In 1950 some $40 \%$ of the population was engaged in farming and forestry and $20 \%$ in industry. In 1975 the corresponding figures were 15 and $27 \%$. The main industries are paper and pulp (30\% of exports), metals $(24 \%)$, and manufacture of wood products (14\%) (Central Statistical Office of Finland, 1981).

\section{THE FINNISH REGISTER OF CONGENITAL MALFORMATIONS}

Most of the studies reported in this survey are based either on data collected by the Finnish Register of Congenital Malformations (FRCM) or on special studies based on its system. This FRCM national surveillance program was established in 1963, and after a pilot year it has functioned unaltered in its original design. The organization has been described in detail by Klemetti and Saxén (1970), Saxén and Klemetti (1974), and Saxén et al. (1974).

\subsection{Notification of Malformations}

Notification of all malformations detected during the first year of life became compulsory in 1963. In 1962 the National Board of Health distributed circulars and sets of printed notification forms to all hospitals, physicians, and midwives in the country, and this has since been frequently repeated. In practice these forms are filled in by physicians at the maternity hospitals and their pediatric wards, which cover all deliveries in Finland. Malformations in stillborn children weighing over $600 \mathrm{~g}$ are registered from compulsory death certificates, delivered as photocopies to the FRCM (located at the main office of the National Board of Health), and completed from the pathologist's autopsy records.

The primary notification lists the names and dates of birth of the mother and child, a description of the delivery, and the malformation type of the child. The malformation type is also checked against a printed list classifying malformations according to the International Classification of Diseases. 


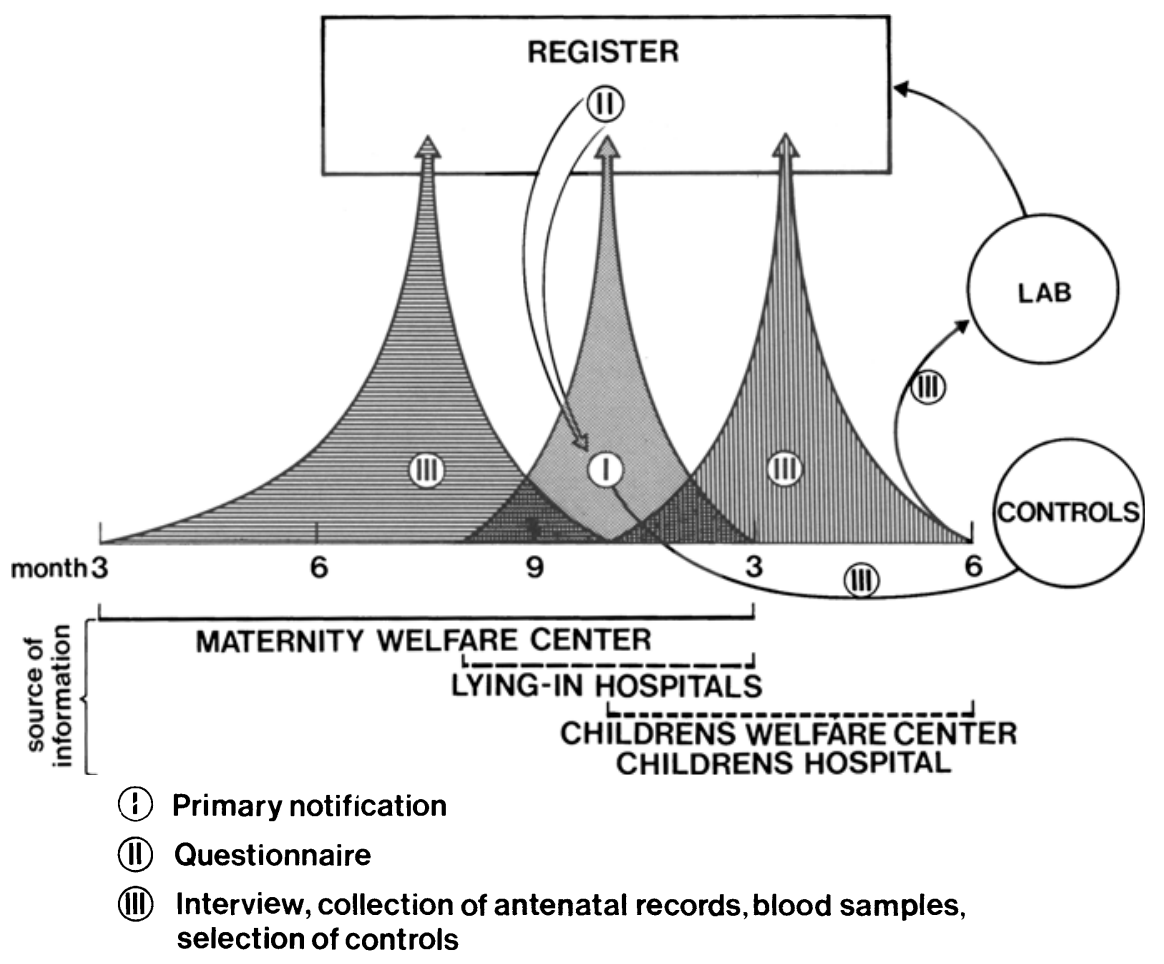

Figure 2. Scheme of the surveillance and matched-pair screening system of the Finnish Register of Congenital Malformations. After Saxén (1977b).

\subsection{Matched-Pair Register}

A systematic study of certain indicator defects (Section 5.1) was introduced in 1964. These malformations are selected immediately from the primary notifications upon receipt by a trained pathologist and include all defects of the CNS, oral and facial clefts, and structural malformations of the skeleton excluding clubfoot and congenital dislocation of the hip. For special studies some other indicator defects have recently been added.

Information on these selected cases and their families is basically collected from two sources: the records of the antenatal and perinatal care units (the Maternity Welfare Centers, MWC), and a personal interview performed soon after delivery (Fig. 2).

\subsection{Maternal and Child Health Organization}

The Maternal and Child Health organization ( $\mathrm{MCH}$ ) was introduced in 1944 , and covers the whole country (Pitkänen, 1964). Accordingly, the country is 
divided into 1300 districts, each with a Center operated on communal basis and staffed by a physician and one or more midwives or public health nurses. Attendance and services at the Centers are free. The Maternity Act grants a benefit to those mothers who visit the Centers before the end of the fourth month of pregnancy, and therefore the first contact is usually made before this stage (Fig. 3). The average number of visits per pregnancy is 18 . In 1964 attendance was $97.5 \%$ and since 1978 close to $100 \%$ (National Board of Health, 1982).

The antenatal care units keep a detailed record of each visit, and these include all results of the physical and laboratory examinations, all diagnostic mea-

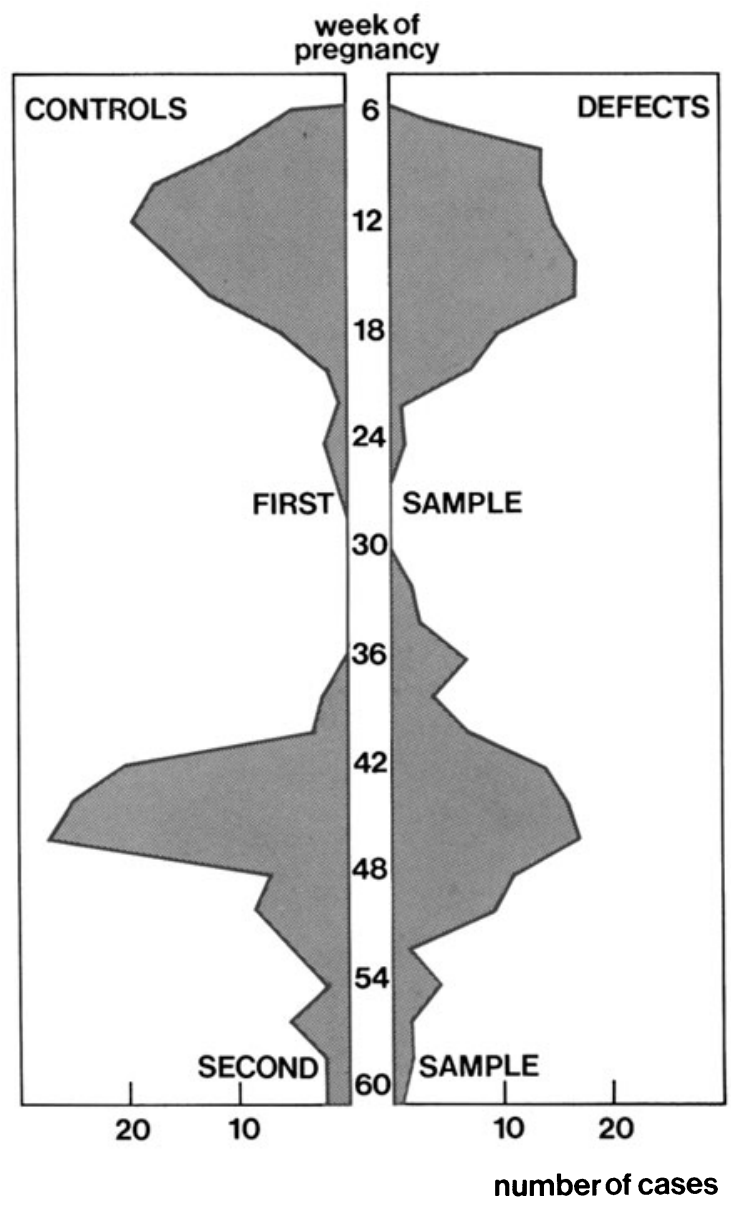

Figure 3. Stage of pregnancy of the control and study mothers at their first visit to the antenatal care unit (Maternity Welfare Center) and at the first postdelivery contact with the same organization. Determined by the dates of the blood samples as reported by Lapinleimu et al. (1972). 
Table I. Factor: Analyzed in the Matched-Pair Screening Study

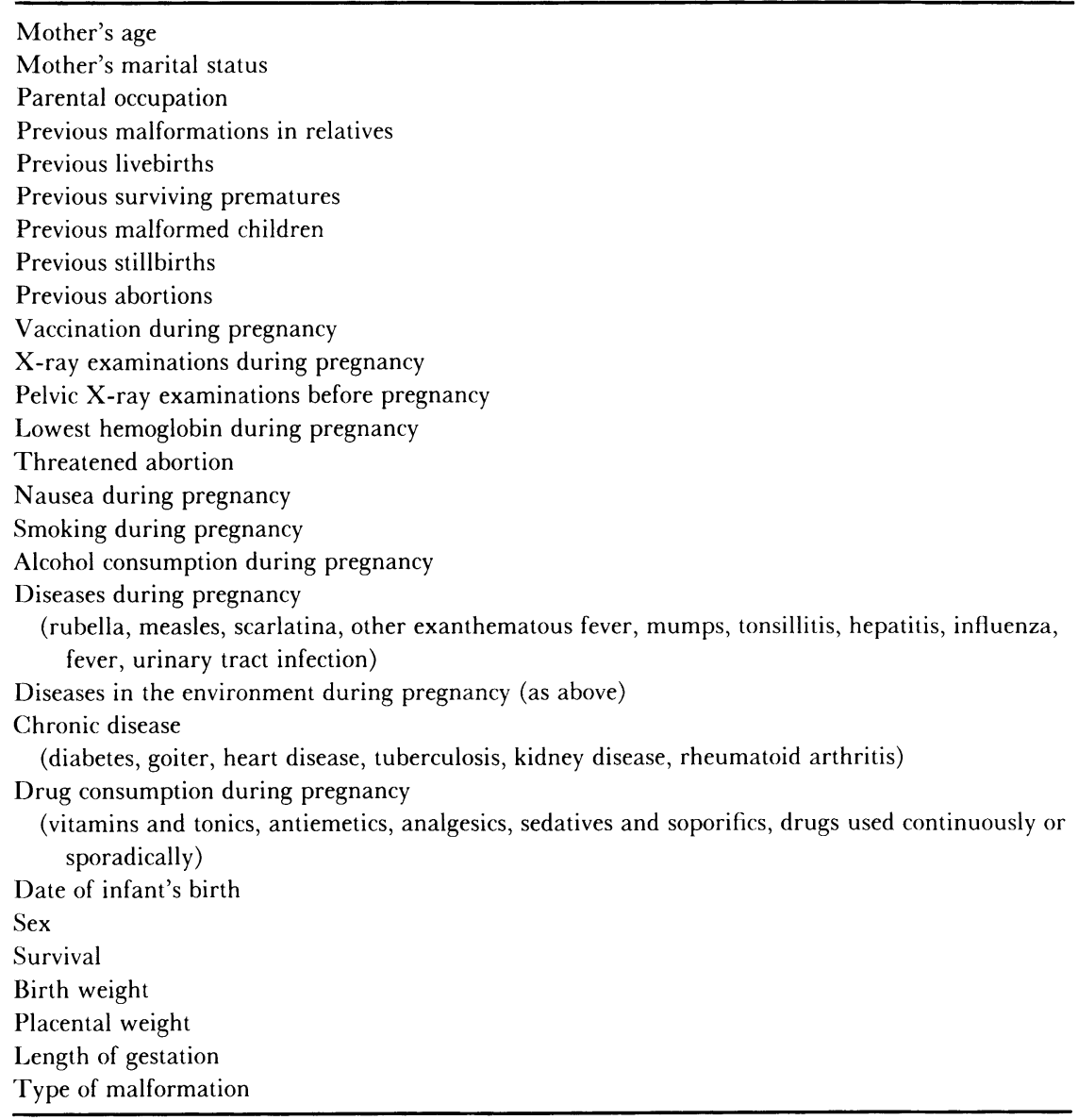

sures, and drugs prescribed. In addition, the mother's family history is recorded, as are data on previous pregnancies, stillbirths, abortions, and other pregnancy complications. Finally, the course of delivery and the condition of the child are recorded before the newborn is enrolled in the Child Welfare organization. The matched-pair register is provided with photocopies of the complete records of the MWC on mothers selected for indicator defect studies.

\subsection{Interview}

The above information from the antenatal records is completed by a personal interview of the mother soon after delivery. This is performed by a trained mid- 
wife or nurse at the MWC with detailed instructions on how to interview and how to fill out the questionnaire. The main items are listed in Table I. This interview is performed as soon as possible, usually not later than 3 months after delivery (Fig. 3).

\subsection{Controls}

For each mother a matched-pair control mother is chosen, whose delivery immediately preceded that of the study mother at the same Maternity Welfare District. Thus the controls are time-area matched, but no other criteria are used in choosing them. In practice the MWG receives the questionnaire in duplicate with different colors for the study and the control mother, and all information for the two is identically collected. Similarly the antenatal records of the control mothers are sent to the Register.

Only cases with all four sets of documents (antenatal records and completed questionnaires on the two mothers) are accepted in the statistics. The success of this procedure is shown in Table II, and the very high response calls for comment: the people and medical personnel in Finland are well-educated, cooperative, and easy to reach through the $\mathrm{MCH}$ organization. In addition, feedback is frequently provided in the national medical journals, and, most important, the midwives responsible for the activity are under the official control of the Register staff.

Table II. Annual Number of Questionnaires Sent to the Mothers of Children with Indicator Defects and to Their Matched Control Mothers

\begin{tabular}{ccc}
\hline Year & Number of questionnaires sent & Recovery rate, $\%$ \\
\hline 1964 & 344 & 97.4 \\
1965 & 239 & 92.5 \\
1966 & 200 & 95.5 \\
1967 & 350 & 97.7 \\
1968 & 314 & 98.7 \\
1969 & 376 & 97.1 \\
1970 & 372 & 97.3 \\
1971 & 352 & 97.7 \\
1972 & 265 & 97.7 \\
1973 & 310 & 97.4 \\
1974 & 329 & 97.6 \\
1975 & 358 & 99.4 \\
1976 & 323 & 100.0 \\
1977 & 349 & 100.0 \\
1978 & 319 & 99.4 \\
1979 & 361 & 98.9 \\
1980 & 453 & 98.2 \\
& Total 5614 & Mean 97.8 \\
\hline
\end{tabular}




\subsection{Blood Samples}

A blood sample is collected after delivery from each study and control mother. The samples are sent to the Public Health Institute, where they are separated, inactivated for $30 \mathrm{~min}$ at $56^{\circ}$, and stored at $-20^{\circ} \mathrm{C}$ (Lapinleimu et al., 1972).

\subsection{Treatment of Material}

All the material from the above sources is coded at the FRCM and prepared for computer analysis. The coding is performed by specially trained personnel. In the special studies all reported drugs are registered according to their active constituents. Different statistical methods are used for the treatment of the data, and these will be mentioned in connection with the respective studies.

\subsection{Special Studies}

The above paragraphs have described the routine procedure of the FRCM and of its matched-pair register. Selected results of the analysis of this material are described below. Several special studies have also been designed and completed within the Register or by using its organization for supplementing the routinely collected data with additional information from various sources. Examples of such investigations are also included in this survey.

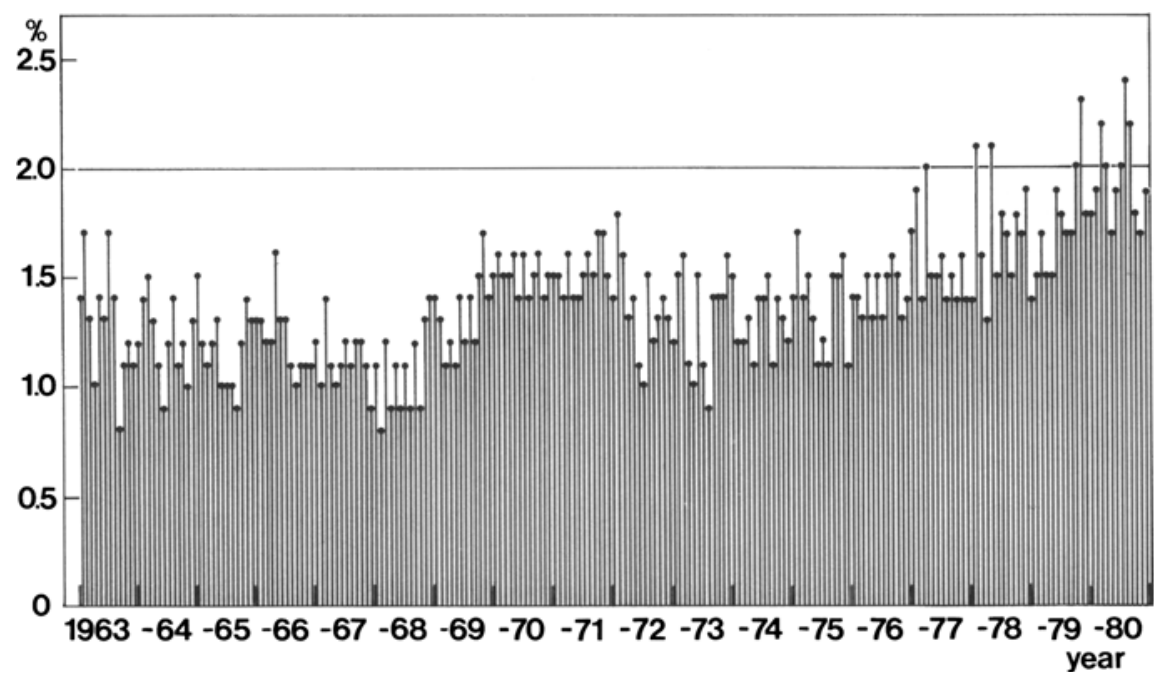

Figure 4. All notified congenital malformations in newborns by month in 1965-1980. After National Board of Health (1982). 


\section{INCIDENCE OF CONGENITAL MALFORMATIONS}

\subsection{Pilot Study}

With the onset of the actual surveillance program, a retrospective hospital study was performed in Finland covering the years 1957-1962 (Saxén and Härö, 1964). Official death statistics were completed by a questionnaire sent to all maternity hospitals and wards by the National Board of Health. All congenital malformations detected and recorded at birth or during the perinatal period were asked to be reported. A statistically significant increasing trend from 1.61 to $2.06 \%$ was observed, but it was concluded to be mainly due to increased interest in the problem. The figures provide, however, a good reference for the evaluation of the data subsequently collected by the FRCM.

\subsection{Malformations Registered in $1963-1980$}

Figure 4 and Table III summarize the results of the Finnish surveillance program up to 1980. Again an increasing trend occurred, but the overall figures remained low, suggesting underreporting when compared with the results of the pilot study. The magnitude of this underreporting can be roughly calculated by comparing the figures in Table III with some previous hospital studies in Finland. Table IV summarizes some of the results that were considered comparable with the FRCM data as far as population and definitions are concerned.

A comparison of the data from these various sources reveals a reporting defect of $30 \%$, assuming that the true incidence of malformations detectable at birth is $2.0 \%$ (Table IV). The situation seems to have slowly improved, and during the most recent years the reporting failure rate was of the order of $15 \%$. To this inaccuracy a true detection failure should be added, and to estimate its magnitude, two follow-up studies were performed.

\subsection{Follow-Up Studies}

To evaluate the "missed cases," two follow-up series were collected. Both were based on relatively limited material, but they may have profited from the fact that each study was performed by a single person following the cohort for 7

Table III. Malformations in Newborns Reported to the Register of Congenital Malformations in 1963-1981

\begin{tabular}{ccc}
\hline Number of children & Malformations reported & Incidence \\
\hline $1,304,276$ & 18,146 & $1.39 \%$ \\
\hline
\end{tabular}


Table IV. Incidence Figures for Congenital Malformations Obtained in Four Hospital Studies in the Finnish Population

\begin{tabular}{llcc}
\hline \multicolumn{1}{c}{ Reference } & \multicolumn{1}{c}{ Years } & Number of children & $\begin{array}{c}\text { Malformation } \\
\text { incidence, \% }\end{array}$ \\
\hline Timonen et al. $(1968)$ & $1957-1958$ & 51,298 & 2.09 \\
Saxén et al. $(1960)$ & 1958 & 6,136 & 2.37 \\
Saxén and Härö $(1964)$ & $1957-1962$ & 467,464 & 1.86 \\
Hirvensalo and Hjelt $(1963)$ & $1961-1962$ & 14,091 & 4.30 \\
\hline
\end{tabular}

and 10 years, respectively. All structural malformations, functional defects, and minor anomalies were recorded from different sources.

Hakosalo (1973) based his study on regional organization of health care in Finland. He assumed that the vast majority of children born in the district of Helsinki (Department of Obstetrics, University of Helsinki) would subsequently be enrolled in the Child Welfare Centers and the pediatric wards of this district. From various control measures he estimated that this method covered $80 \%$ of the 6000 consecutive deliveries of the original cohort. The observed cumulative frequency distribution of the various types of defects is shown in Fig. 5.

Klemetti $(1966,1978)$ chose her cohort from a stable, predominantly rural population of a county in central Finland with only one central hospital with obstetric and pediatric wards. The cohort consisted of 3674 children followed from their early intrauterine development (prospective pregnancy study) up to the age of 7 years. The success rate in the follow-up was $82 \%$. Figures (Fig. 5 ) of the cumulative frequency seem to have lagged slightly behind those of Hakosalo (1973) despite the same definitions and follow-up rate. Apparently the material at a University Hospital is somewhat different from that of a small central hospital in a predominantly rural area.

In conclusion, the "true" incidence of structural malformations in the Finnish population is of the order of $3 \%$, of which two-thirds are detected at birth. Hence the failure rate in detection is of the order of $30 \%$.

A similar accumulation of late detectable malformations has been shown in other studies with various populations and different health care systems (Neel, 1958; McDonald, 1961; Coffey and Jessop, 1963; Mellin, 1963). A detailed comparison of our figures with these findings is difficult to make because of differences in the definitions and classifications of the defects.

\subsection{Failures in Reporting and Detection}

It was concluded above that the Finnish surveillance system is suffering from an underreporting of some $50-55 \%$ due to defective reporting and detection during 

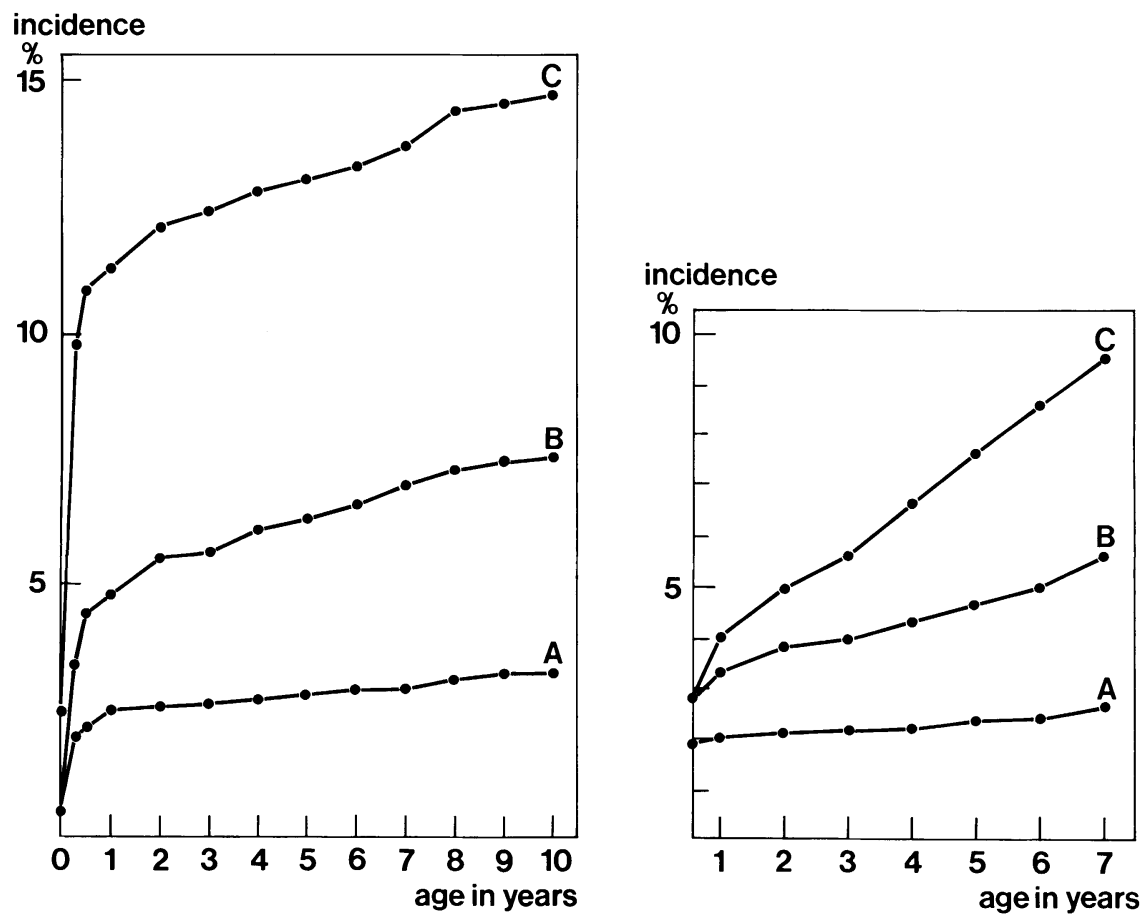

Figure 5. Cumulative detection rates of congenital defects in the follow-up studies by Hakosalo (1973) (left) and Klemetti (1978) (right). A, structural malformations. B, congenital defects. C, all congenital anomalies.

early childhood. The failure rate is naturally different in different groups and types of defects, and it is probably related to the severity and clinical significance of the malformation (Weatherall, 1970; Mackeprang and Hay, 1972). It is smaller for the severe, lethal defects like anencephaly.

In one particular instance it was possible to evaluate with a high degree of accuracy the proportion of cases unknown to the Register. Since 1947 the treatment of children with cleft lip or palate has been centralized to a single surgical unit, which keeps detailed records of all cases of these defects, including those detected during later stages of life. When these records were compared with the figures of the FRCM from the years 1967-71 (Saxén and Lahti, 1974), a failure rate of $23.5 \%$ was noted. The authors attributed this mainly to the failure to detect minor forms of these defects, especially that of the submucous cleft palate (Rintala and Stegars, 1982). 


\subsection{Trends and Seasonal Variations}

Because of the increasing interest in congenital defects and the improvement of diagnostic measures and surveillance programs, all long-range changes in the overall incidence of defects should be treated with great caution. Hence, the trend toward increase (Fig. 4) might be less informative than the results of some special studies focusing on single malformations or defined groups (e.g., Fraser, 1971). In the above-mentioned study by Rintala and Stegars (1982), the incidence of cleft lip and palate was shown to increase constantly with an annual rate of $1 \%$ (from 1948 to 1975 ).

Hemminki et al. (1982) perused the files of the FRCM to follow the incidence of gastroschisis. As in the other Scandinavian countries, an increase was observed in the 1970 s (from $0.77 / 10,000$ to $1.42 / 10,000$ ), while the values for omphalocele remained constant. It is not possible, however, to decide the extent to which this is a reflection of an increased reporting rate. Based on $1235 \mathrm{limb}$ defects filed by the FRCM in 1964-1977, Aro et al. (1982) found that their incidence had doubled during this period. Since the reporting rate had apparently improved during this time, the authors calculated the relative proportion of limb defects to all malformations, but still detected a significant increasing trend (from 9 to $12 \%$ of all defects).

A detailed analysis of the seasonal variations in the incidence of defects in the three indicator groups revealed only insignificant differences. The negative finding with regard to anencephaly is of interest (Granroth et al., 1977). Based on an observed seasonal variation in the incidence of this malformation, Renwick (1972, 1973) postulated that some factor(s) in stored, blight-infested potatoes might be involved. In Finland the storage of potatoes is extended because of the long winter season, and the consumption of potatoes is among the highest recorded (263 g/ day in 1970). Yet the relatively reliable incidence figures obtained from death certificates show a very low incidence of anencephaly in Finland $(3.2 / 10,000)$ and no seasonal variations. Thus, our results do not lend support to the much discussed hypothesis of blighted potatoes.

A seasonal variation in the incidence of both cleft lip and cleft palate was reported by Saxén and Lahti (1974). This might, however, reflect a chance observation, as the same author could not confirm the findings in a subsequent analysis in the same population (Saxén, 1975b). The example suggests that at least some of the reported seasonal variations in the incidence of congenital defects might belong to the category of chance findings and should, therefore, be confirmed in other, independent studies.

\subsection{Geographic Distribution}

If local factors were involved in the etiology of congenital malformations one might expect to detect a corresponding clustering of defects within a large country 

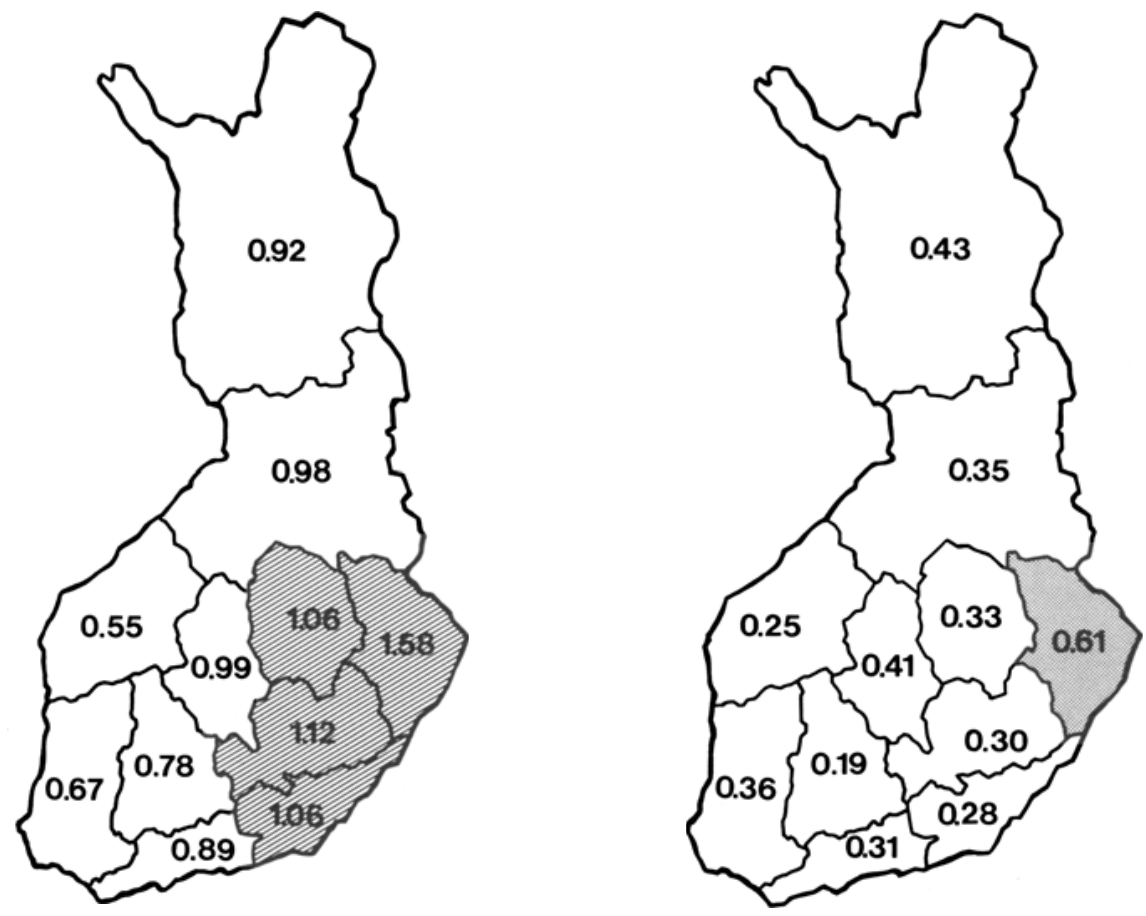

Figure 6. Geographic distribution of cleft palate (left) and anencephaly (right) in Finland. After Saxén and Lahti (1974) and Granroth et al. (1977).

like Finland, where the mode of life, social stratification, climate, soil, and other parameters vary greatly (Teppo et al., 1980). Such possible findings are, however, sensitive to factors affecting the reporting and detection rates. Therefore, only two efforts have been made to study the matter. Since it seems that both cleft palate (excluding minor forms) and anencephaly are relatively well detected and reported, their geographic distribution was mapped. Both were shown to follow an east-west gradient, with a maximum in the county of North Carelia (Fig. 6). A causative explanation for this finding might be found in Table XVI.

\section{THE MATCHED-PAIR REGISTER}

\subsection{Indicator Defects}

Owing to the difficulties of detecting and classifying congenital defects and to the consequent problems in comparative studies, it was decided to focus on certain 
indicator defects already mentioned. These represent structural malformations caused by impaired organogenesis during early development and are detectable with relatively simple diagnostic measures which do not change in time and place. The type and number of these defects are indicated in Table V.

\subsection{Risk Indicators}

The associations between the indicator defects in Table $\mathrm{V}$ and the variables listed in Table I have been tested in several connections without an actual working hypothesis. Ordinary screening methods were used, and the results were regularly compared with the control material, which either consisted of pooled matched pairs or was performed by examining discordant pairs. Table VI summarizes some associations in the three groups of defects. These data and some control studies that tested their validity will be discussed in Sections 5.2.1-5.2.6.

\subsubsection{Maternal Age}

Maternal age beyond 35 years was significantly associated with an elevated malformation risk in the groups with CNS defects and oral clefts, a finding not unexpected and frequently reported (Record, 1961; Hay and Barbano, 1972; Fedrick, 1976). As will be shown in Section 7.5, our matching system might not be ideal for analysis of parental age factors, and hence a complementary study was

Table V. Indicator Defects Selected for the Matched-Pair Register of the Finnish Register of Congenital Malformations

\begin{tabular}{lccr}
\hline & Only defect & Additional defects & Total \\
\hline Defects of the CNS & & & \\
$\quad$ Anencephaly & 162 & 37 & 199 \\
Spina bifida & 164 & 75 & 239 \\
Hydrocephaly & 164 & 52 & 216 \\
Others & 40 & 16 & 56 \\
Total & & & 710 \\
Cleft lip and palate & & 134 & \\
Cleft lip & 232 & & \\
& & & \\
Cleft palate & 232 & 124 & \\
Total & & - & 599 \\
Defects of the limbs & & - & 299 \\
$\quad$ Reduction deformities & 329 & & 1311 \\
$\quad$ Polydactyly & - & & \\
Syndactyly & - & & \\
Total & & & \\
\hline
\end{tabular}


Table VI. Some Significant Associations between Maternal Histories and Three Groups of Congenital Defects ${ }^{a, b}$

\begin{tabular}{lccr}
\hline & $\begin{array}{c}\text { CNS } \\
\text { defects }\end{array}$ & $\begin{array}{c}\text { Skeletal } \\
\text { malformations }\end{array}$ & $\begin{array}{r}\text { Oral } \\
\text { clefts }\end{array}$ \\
\hline Maternal age $>40$ years & $\begin{array}{r}\times \times \\
\times \times\end{array}$ & $\times \times$ & $\times \times$ \\
Unmarried mother & $\times \times \times$ & & $\times \times$ \\
Previous abortions & $\times \times$ & $\times$ & \\
Previous stillbirths & $\times \times \times$ & $\times \times$ & $\times \times$ \\
Previous defects in children & $\times \times \times$ & $\times \times \times$ & $\times \times \times$ \\
Threatened abortion & $\times \times \times$ & $\times \times \times$ & $\times \times \times$ \\
Birth weight $<2500 \mathrm{~g}$ & & & $\times \times \times$ \\
Maternal influenza during first trimester & $\times \times \times$ & $\times \times$ & $\times \times \times$ \\
Maternal intake of drugs, first trimester: & $\times \times \times$ & $\times \times \times$ & $\times \times \times$ \\
$\quad$ Overall & & & $\times \times \times$ \\
Analgesics & & & \\
Penicillin & & & \\
\hline
\end{tabular}

${ }^{a}$ Saxén et al. (1974).

${ }^{b} \times, P<0.05 . \times \times, P<0.01 . \times \times \times, P<0.001$.

conducted. Various defect groups collected from the FRCM were compared with material from the whole country, i.e., with 399,205 mothers from the years 19631967 (Hämäläinen et al., 1970). The curves of maternal age distribution for various groups of malformations were plotted against the curve for all mothers (Fig. 7). A rather good fit was observed for cleft palate, skeletal defects, and congenital dislocation of the hip, whereas the curves for CNS defects and malformations of the circulary system showed a deviation toward the older age groups. The shape of the curve for Down syndrome is naturally an extreme.

\subsubsection{Previous Abortions, Stillbirths, and Malformed Children}

Information on an abnormal outcome in one or several previous pregnancies seemed to be another risk indicator for CNS defects and skeletal malformations. Whether these indicators reflect a constitutional defect of the mother, genetic defects in the children, or continuous exposure to an unfavorable environment (working conditions, alcoholism, etc.) remains open, but that does not lessen the importance of the indicators where delineating a maternal group with an elevated risk of having a malformed child.

\subsubsection{Familial Occurrence}

The material of the FRCM does not include data on actual familial analysis of the malformations, but in some instances the role of genetic versus exogenous 

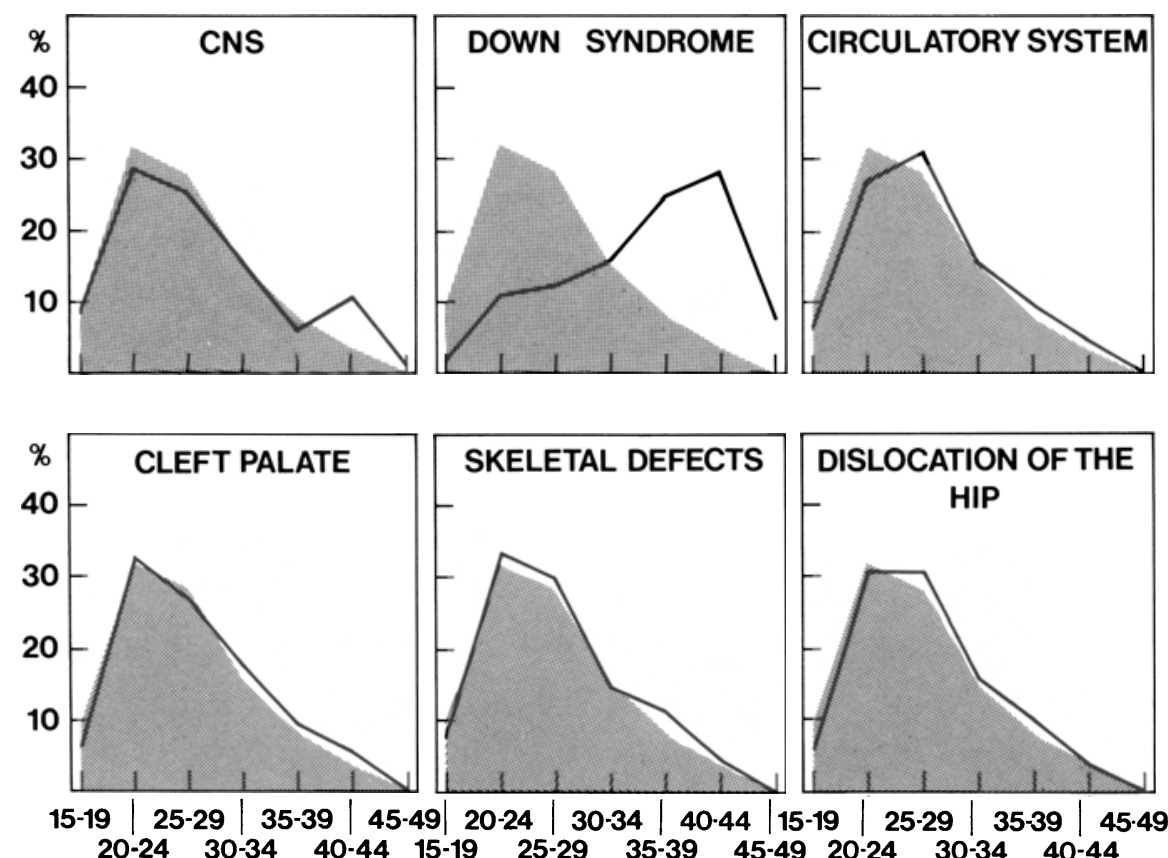

Figure 7. Maternal age distribution of different groups of malformations compared with the curves for all mothers in Finland (hatched area). After Hämäläinen et al. (1970).

factors can be roughly estimated. Two examples related to polydactyly, a defect of definite familial trend, will be given.

To test the effect of exogenous factors in two groups of defects, those of the CNS and polydactyly, the $\chi_{(1)}^{2}$ test was used for 40 test values (Fig. 8). Compared with the theoretical $\chi_{(1)}^{2}$ distribution, the deviation should be the greater the stronger the association between the variable and the defect. The observed values for CNS defects were different from the theoretical ones with a high degree of significance $(P<0.01)$, whereas those for polydactyly showed clearly smaller differences $(P<0.05)$, thus suggesting the importance of factors other than those tested.

Polydactyly was also used as an internal control when the role of a hereditary factor was evaluated in the group with limb reduction defects. The interviewed mothers had given information only on the number of affected family members, whereas the total number remained unknown, as it was not possible to evaluate how far the mothers' memory reached. Hence, a type distribution analysis was made (Fig. 9). The results clearly show that in the polydactyly group the majority of defects in the family were of the same type, whereas in the limb reduction defect 
group the different types of malformations seemed to be more randomly distributed in the family. The results suggest that hereditary factors play no major role in the reduction defects (Aro et al., 1983).

\subsubsection{Threatened Abortion}

Recorded "vaginal bleeding" or "threatened abortion," measuring the same condition, proved to be associated with defects in all groups (see also RumeauRouquette et al., 1971). It is difficult to judge which of three mechanisms we are

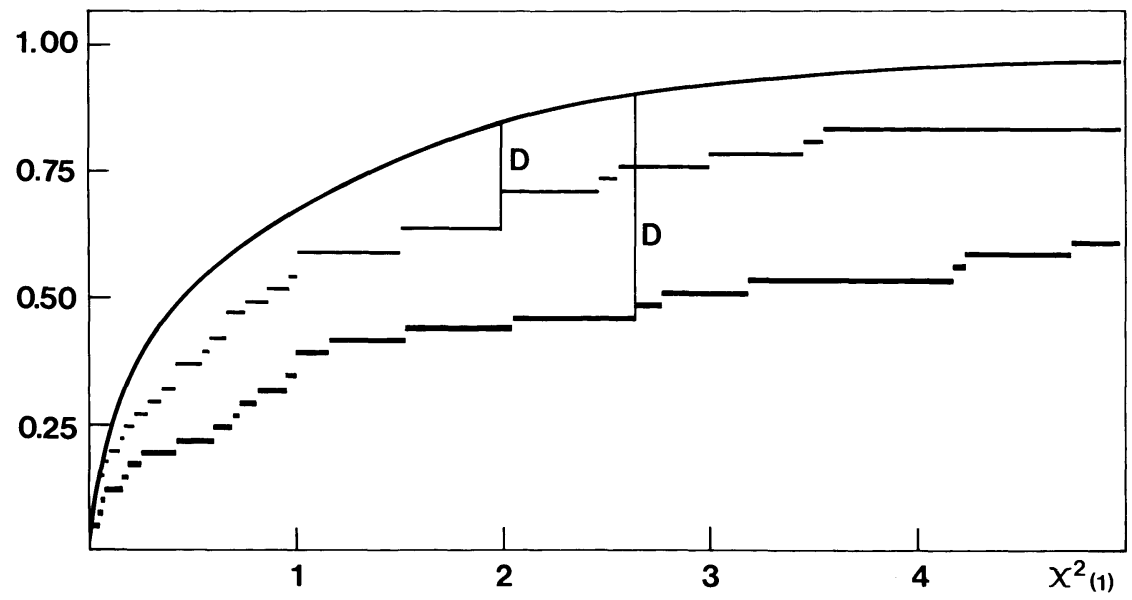

Figure 8. Theoretical distribution function of $\chi_{(1)}^{2}$ (solid line) compared with the observed distribution function of $\chi_{(1)}^{2}$ test values for CNS defects (lower broken line) and polydactyly (upper broken line). D, Maximum difference. After Granroth (1978).

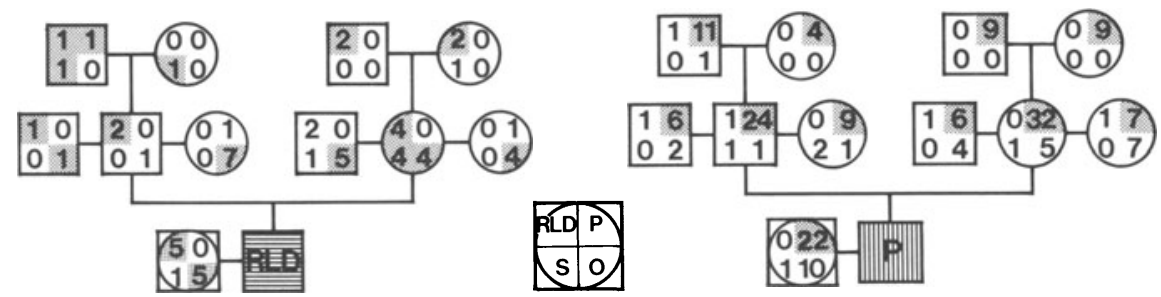

Figure 9. Analysis of the type of defect reported in the family by mothers of children with reduction limb defects (RLD) and polydactyly (P). In addition, cases of syndactyly (S) and other malformations $(\mathrm{O})$ are indicated. The hatched quarter indicates the type of defect most frequently reported. After Aro et al. (1983). 
dealing with: the condition itself may cause a disturbance in fetal development; the signs of a threatened abortion and a fetal defect may be caused by the same factor; or the threatened abortion may be a sign of fetal discomfort due to an already existing defect. The third possibility sounds most feasible and is supported by the finding that embryos obtained after completed abortions during early pregnancy show a high incidence of malformations (Nishimura et al., 1966).

To analyze these alternatives further, an effort was made to compare individually the time of bleeding with the probable "sensitive period" of the defects. This was done for the group of limb reduction defects, as these seemed to be the only ones whose sensitive period for human embryos could be roughly estimated from the data for the thalidomide cases (Fig. 10). Consequently, our 40 cases of these reduction defects could be divided into three groups: those where the bleeding was recorded prior to the vulnerable period with mainly minor defects, those where the two coincided with mainly severe or multiple defects, and those where the bleeding was reported after the sensitive period. The last group probably reflects an earlier induction of a severe defect later leading to an effort to expel the embryo. The second group might include cases where bleeding and defects have a common cause.

\subsubsection{Influenza during Early Pregnancy}

True viral influenza has frequently been associated with fetal damage, especially with CNS defects (Coffey and Jessop, 1959; Saxén et al., 1960; Hardy et al., 1961; Leck, 1963). Our data lend further support to this view. However, two points must be stressed: as the information on maternal "influenza" was mainly obtained during postdelivery interviews, the entity certainly consists, in addition to actual viral diseases, of various feverish conditions ("flu"). Hyperthermia as such has been mentioned as a possible teratogen (McDonald, 1961; Miller et al., 1978; Layde et al., 1980), and it could also be a causative factor here. Furthermore, influenza and fever are usually linked with medication, which confounds the study situation. An analysis of this confounder is presented in Section 7.3.

\subsubsection{Drug Intake during Early Pregnancy}

It is not necessary here to review the voluminous literature on drug-induced teratogenesis; one can state that exposure to drugs and environmental chemicals during pregnancy is a central problem today. It is also one of the most difficult problems to approach, and both epidemiologic and experimental investigations have revealed controversial results sometimes leading to hasty practical consequences. Of the thousands of chemicals to which a pregnant woman might become exposed, only a handful have been proven hazardous for the embryo [for reviews 


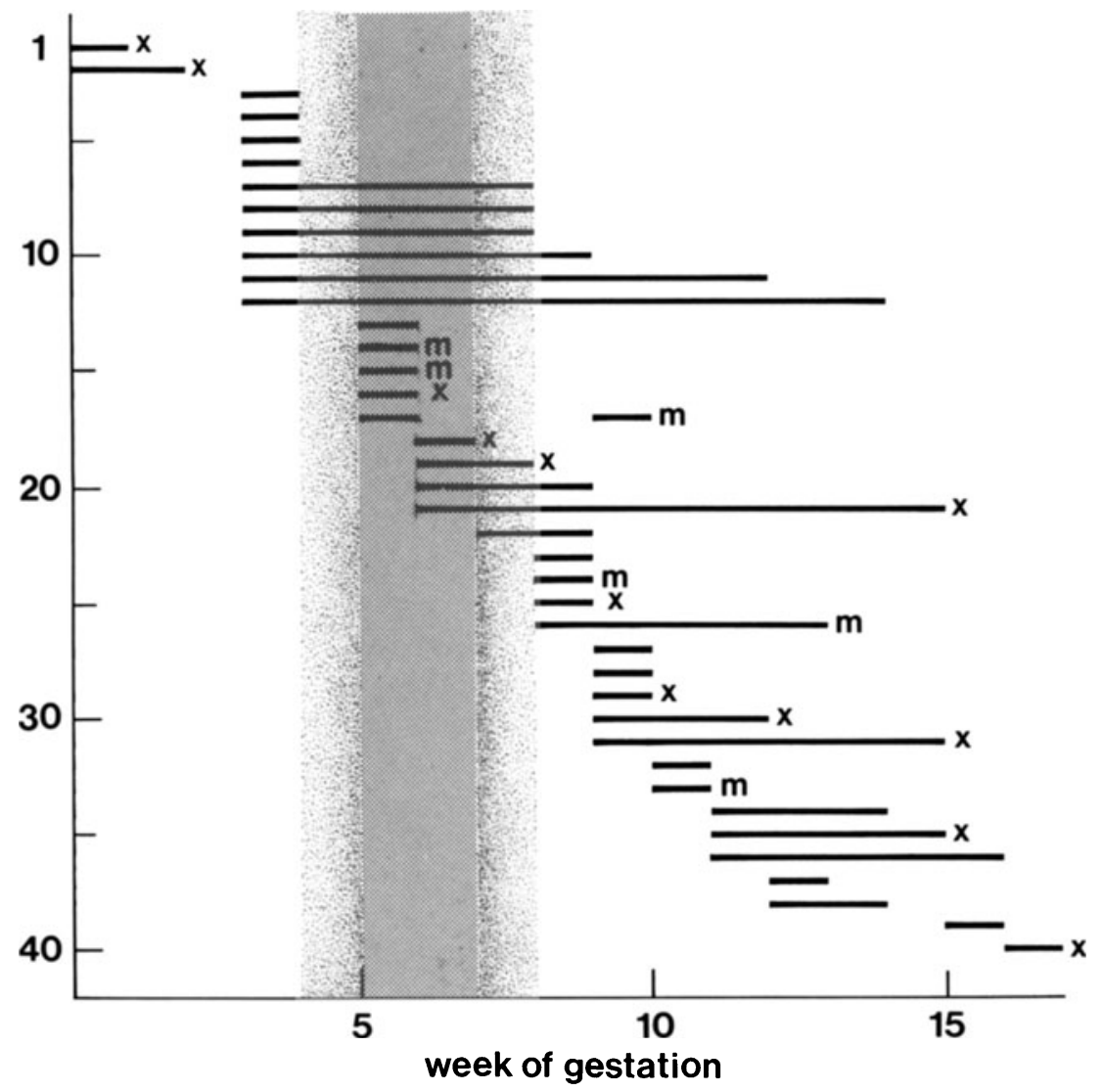

Figure 10. Individual analysis of the time of vaginal bleeding in mothers of children with limb reduction defects. Hatched area: estimated sensitive period for thalidomide-induced limb reduction defects [after Nowack (1965)]. m, Major defects. x, Multiple defects. After Aro et al. (1983).

see Saxén and Rapola (1969), Wilson (1973), Smithells (1976), Saxén, (1977a)] and the number of those proven safe is also small. In the following only a few examples of our studies related to this problem are described.

The overall consumption of drugs during pregnancy among Finnish mothers approaches $50 \%$. During the sensitive early pregnancy there is a highly significant difference between the study and control mothers, which gradually evens during late gestation (Table VII).

Intake of salicylates during early pregnancy was found to be significantly associated with all defect groups studied (Saxén and Klemetti, 1974; Saxén, 1975a; Granroth, 1978), and the risk ratio is of the order of three. It is difficult 
to conclude whether this regularly found association is truly causative, but multivariate analyses performed seem to rule out the probable confounders (Saxén, 1975c; Granroth et al., 1978). On the other hand, the series of CNS defects analyzed by Granroth (1978) also revealed a significant association between salicylate intake and polydactyly, a finding that arouses suspicion of maternal memory bias (to be dealt with in Section 7.2).

Diazepam as a teratogen was first pointed out by the Atlanta Register (Safra and Oakley, 1975), and after an oral message from Dr. Oakley the matter was rapidly examined in the material of the FRCM. A confirmatory association between the uptake of diazepam during the first trimester and oral clefts was observed. (Saxén and Saxén, 1975). However, the number of cases remained small, and no multivariate analysis to eliminate possible confounders has thus far been performed. The finding represents a suggestive association to be tested in other materials.

In 1972 a few cases were published in which an association between the intake of imipramine and abnormal fetal outcome was suggested (McBride, 1972). Remarkable public attention arose, and the matter was soon examined in several materials, one of them being the routinely collected data of the FRCM. Close to 3000 maternal pairs were analyzed in a few weeks, but only three cases were found where the study mother had taken the drug during early pregnancy. None were found in the control group (Idänpään-Heikkilä and Saxén, 1973). Again the finding remains inconclusive and should be reevaluated in other epidemiologic studies. The two last examples, diazepam and imipramine, demonstrate how a data bank such as the routinely collected register of the FRCM can rapidly be perused and consulted when a new hypothesis is launched elsewhere.

Conflicting reports of the possible teratogenicity of oral contraceptives used prior to or during early pregnancy (Peterson, 1969; Carr, 1970; Robinson, 1971; Poland and Ash, 1973; Royal College of General Practitioners, 1976) prompted a study of 3002 maternal pairs collected from the matched-pair register from the years 1967-1976 (Savolainen et al., 1981). Analysis of the discordant pairs (Table VIII) lent no support to the hypothesis that oral contraceptives harm the embryo.

Table VII. Percentage of Overall Drug Intake by the Study and Control Mothers during Different Trimesters of Pregnancy $^{a}$

\begin{tabular}{llc}
\hline \multicolumn{1}{c}{ Stage } & \multicolumn{1}{c}{ Study mothers } & Control mothers \\
\hline First trimester & $45.4(P<0.001)$ & 27.2 \\
Second trimester & $35.9(P<0.05)$ & 30.4 \\
Third trimester & 43.9 & 41.7 \\
\hline
\end{tabular}

${ }^{a}$ Saxén $\left(1975^{a}\right)$. 


$\begin{gathered}\text { Table VIII. Analysis of Discordant Pairs As } \\
\text { to the Use of Oral Contraceptives (OC) } \\
\text { among Mothers of Malformed Children and } \\
\text { Their Matched Pairs }{ }^{a, b}\end{gathered}$
\begin{tabular}{lcr}
\multicolumn{2}{c}{ Controls } \\
\cline { 2 - 3 } Cases & No OC & With OC \\
\hline No OC & 2219 & 461 \\
With OC & 439 & 153 \\
\hline
\end{tabular}

${ }^{a}$ Savolainen et al. (1981).

${ }^{b}$ Risk ratio: 0.95 . The $95 \%$ confidence interval is $0.86-1.05$.

When different groups of defects were analyzed separately the distribution of users and nonusers among the study and control mothers was remarkably similar.

\section{SPECIAL STUDIES}

Thus far, all results presented were extracted from the routinely collected data of the Finnish surveillance program. The theoretical and practical significance of these findings will be discussed toward the end of this survey, as will the limitations and possible errors inherent in the program. Before that, however, I will describe some examples of special, mostly preplanned, studies using the basic organization of the FRCM.

\subsection{Occupational Hazards}

The original questionnaire of the matched-pair register did not include items directly related to maternal hazards of the workplace. There are two reasons for this: in 1961-1963, when the questionnaire was designed, occupational hazards were considered less important, but it was also felt that in order to collect adequate data on such risk factors a more detailed interview should be performed. As we have subsequently learned, such interviews are laborious and cannot-and should not-be included in a routine checking list.

However, the antenatal records of the study and control cases in the matchedpair register give the parental occupations, and were analyzed by Hemminki et al. $(1980,1981)$. A total of 3300 pairs were coded for their occupations and classified into 11 groups. A significant association was found between maternal employment in industry and defects of the CNS and skeleton as well as oral clefts. This could represent a causative association, but a chance correlation is difficult 
to rule out. Hence, other approaches for examining maternal occupational hazards have been used.

In 1976 a special interview study was devised to analyze occupational hazards during pregnancy (Holmberg and Kurppa, 1982). Consecutive cases of indicator defects are selected by the pathologists immediately after reporting to the FRCM, after which a specially trained interviewer from the Institute of Occupational Health is sent to the local Maternity Welfare Center to interview the study mother and her time-area matched control. A specially designed questionnaire consists of both open and fixed questions not restricted to defined hypotheses. Among other things the mother is asked to describe in detail her working conditions, which are recorded and analyzed by trained industrial hygienists, who then classify the material blindly. This ongoing study annually collects approximately 350 pairs of mothers. With an estimated rate of 5\% exposure to environmental conditions under study, series large enough for conclusive findings require several years of data collection. Thus far only certain organic solvents have shown a suggestive association to malformations (Holmberg, 1979), whereas many others seem to be equally distributed among the study and control mothers. Among these are the frequently discussed disinfectants, which have shown no associations in the 1000 pairs of mothers thus far analyzed (Kurppa et al., 1982b).

\subsection{Leisure Time}

The special surveillance system just described for occupational hazards is also suitable for studies related to maternal exposure during leisure time. Two such studies have recently been conducted.

\subsubsection{Sauna}

Hyperthermia induced by the Finnish sauna has been suggested as being associated with an elevated risk of CNS defects, particularly of anencephaly (Miller et al., 1978; Smith et al., 1978). The hypothesis was met with considerable scepticism in Finland, where the sauna is an important constituent of everyday life, including during pregnancy (Rapola et al., 1978; Uhari et al., 1979), but where the incidence of anencephaly is among the lowest reported (Granroth et al., 1977). Therefore, a systematic study was initiated by using a special questionnaire including detailed questions on the sauna habits of mothers and on the possible changes in them during pregnancy. In 1978-1980 the trained personnel interviewed 100 reported consecutive cases of CNS defects and 202 cases of oral clefts and their time-area matched control pairs. Four study mothers and five controls had not visited sauna during pregnancy, and these pairs were excluded from the final analysis.

Concerning the frequency of sauna visits, the results of the analysis of discordant pairs are given in Table IX. No differences between the study and the 
Table IX. Analysis of the Discordant Pairs According to the Frequency of Visits to the Sauna During the Recent Pregnancy ${ }^{a}$

\begin{tabular}{|c|c|c|c|c|}
\hline \multirow[b]{3}{*}{ Cases } & \multicolumn{4}{|c|}{ Controls } \\
\hline & \multicolumn{2}{|c|}{ CNS defects } & \multicolumn{2}{|c|}{ Oral clefts } \\
\hline & Weekly & Monthly & Weekly & Monthly \\
\hline Visit weekly & 76 & 10 & 171 & 14 \\
\hline Visit monthly & 9 & 2 & 9 & 2 \\
\hline Risk ratio & \multicolumn{2}{|l|}{1.1} & \multicolumn{2}{|l|}{1.6} \\
\hline $95 \%$ confidence interval & \multicolumn{2}{|c|}{$0.45-2.73$} & \multicolumn{2}{|c|}{$0.68-3.57$} \\
\hline
\end{tabular}

${ }^{a}$ Saxén et. al. (1982).

control mothers were detected. Similarly, when the sauna habits were analyzed in detail (changes during pregnancy, level of temperature, number of exposures, and total length of exposure), they were identical in the study and control groups. Hence, it seemed safe to conclude that the mild, short-term hyperthermia induced by sauna should not be considered hazardous to the embryo (Saxén et al., 1982).

\subsubsection{Coffee}

Reports on the possible embryonic hazards of extensive consumption of coffee during pregnancy are contradictory (Weathersbee et al., 1977; Borlée et al., 1978; Morris and Weinstein, 1981; Linn et al., 1982; Rosenberg et al., 1982). The matter clearly requires further evaluation, especially as we are dealing with a most common exposure of pregnant women. Since Finns are among the heaviest coffee consumers, with an annual per capita consumption of $13 \mathrm{~kg}$ in 1978-1980, the FRCM was used to examine the hypothesis. In 1979 the interviewers were provided with a new questionnaire, now including a series of questions concerning the mother's coffee consumption prior to and during pregnancy. Toward the beginning of 1982 the ongoing study had collected information on 755 maternal pairs. Analysis of the discordant pairs revealed no differences (Kurppa et al., $1982 a$ ), after which calculations were made on the risk levels that could be excluded by this study (Table $\mathrm{X}$ ).

\subsection{Infectious Diseases}

Infectious diseases, particularly viral infections, are known to be hazardous to the developing embryo. Again, there is no need to review the literature of the field, and instead some serologic investigations based on the organization of the FRCM will be briefly summarized. 


\begin{tabular}{|c|c|c|}
\hline & & \\
\hline & 0.05 & 0.01 \\
\hline CNS defects & 3.0 & 4.1 \\
\hline Oral clefts & 2.1 & 2.7 \\
\hline Skeletal defects & 2.2 & 2.8 \\
\hline Cardiovascular defects & 2.5 & 3.4 \\
\hline Total & 1.6 & 1.8 \\
\hline
\end{tabular}

${ }^{a}$ Kurppa et al. (1982).

\subsubsection{Serologic Studies}

Blood samples collected soon after delivery were analyzed for the study and control mothers for a set of viral and microbial antibodies. Twenty-eight antibodies were measured in 162 serum pairs. Antibodies against ECHO 7 virus were found more frequently in the study mothers. Conclusions on the possible causative role of this infection are hampered, however, by the fact that the method does not allow timing of the maternal contamination, which could have taken place at any stage of pregnancy (Lapinleimu et al., 1972). Hence, an effort was made to follow changes in the antibody titers during pregnancy from paired serum samples obtained during and after gestation. This laborious task involved collection of blood samples of a sizable maternal cohort during early pregnancy and their follow-up for evaluation of the pregnancy outcome and for a second blood sample.

In 1969-1973 blood was obtained from 48,000 mothers during their first visit to the Maternal Welfare Center (Fig. 3). It was separated and stored frozen. Of these mothers 274 gave birth to malformed children. Next, blood samples of these study mothers were obtained through the FRCM organization, and a similar sample was obtained from the controls. The first samples from these mothers were then harvested from the stored 48,000 samples. Table XI summarizes the findings in these serum quadruplets. The main finding was that an increasing seroconversion for the herpes virus antibodies occurred more frequently in the study mothers than in their controls. Apart from a similar observation concerning toxoplasma antibodies, other differences were insignificant.

Interpretation of the main observation is difficult, since the positive seroconversion of antibodies against herpes viruses had taken place during late pregnancy, after the malformations had most probably been induced. Therefore, the contamination can hardly be causative, and the authors concluded that the finding was 
most probably due to activation of the latent virus by the severe condition of the fetus or to the same teratogenic condition that had caused the fetal defect (Lapinleimu et al., 1974; Koskimies et al., 1978).

\subsubsection{Smallpox Vaccination}

Related to virus-induced malformations, cases have been published in which smallpox vaccination with living virus caused a deleterious transplacental infection resulting in fetal wastage (Green et al., 1966). The magnitude of the risk is not known, and this was the reason for conducting a special epidemiologic study stimulated by a unique study situation. In May 1963 a case of smallpox was detected in Sweden, and that immediately led to mass vaccination in Finland. The extent and time of the vaccination were determined from the delivery figures of the vaccine at the State Serum Institute, the sole source of the smallpox vaccine in the country. The results (Fig. 11) revealed a brief, high peak in the delivery figures in May 1963. An inquiry performed among pregnant mothers indicated that early pregnancy had not been considered a contraindication for vaccination. The percentage of mothers vaccinated during the first trimester was of the order of $30 \%$. It seemed as if we were dealing with an optimal study situation characterized by a high exposure rate of short duration.

Perusal of the files of the FRCM did not show any elevated incidence of malformations following the vaccination. An early transplacental infection might, however, lead to the loss of the embryo, and an effort was made to estimate the rate of spontaneous abortions soon after the vaccination period. Since it is extremely difficult to obtain reliable abortion information, an indirect approach was chosen. It was based on the sound premise that an increased abortion rate should later be detectable as a reduced birth rate. The data revealed, however, no such effect on the birth rate among mothers of whom $30 \%$ had been vaccinated during early pregnancy (Saxén et al., 1968). This negative finding led us to a

Table XI. Fourfold (or Greater) Changes in Antibody Titers in 274 Mothers of Defective Children and 274 Controls $^{a}$

\begin{tabular}{lcc}
\hline & \multicolumn{2}{c}{ Increases + decreases } \\
\cline { 2 - 3 } \multicolumn{1}{c}{ Antigen } & $\begin{array}{c}\text { Mothers of } \\
\text { defective children }\end{array}$ & Controls \\
\hline Herpes simplex virus 1 & $11+2$ & 5 \\
Herpes simplex virus 2 & $12+1$ & 1 \\
Cytomegalovirus & 21 & $14+1$ \\
Varicella-zoster virus & 9 & 2 \\
\hline
\end{tabular}

${ }^{a}$ Koskimies et al. (1978). 


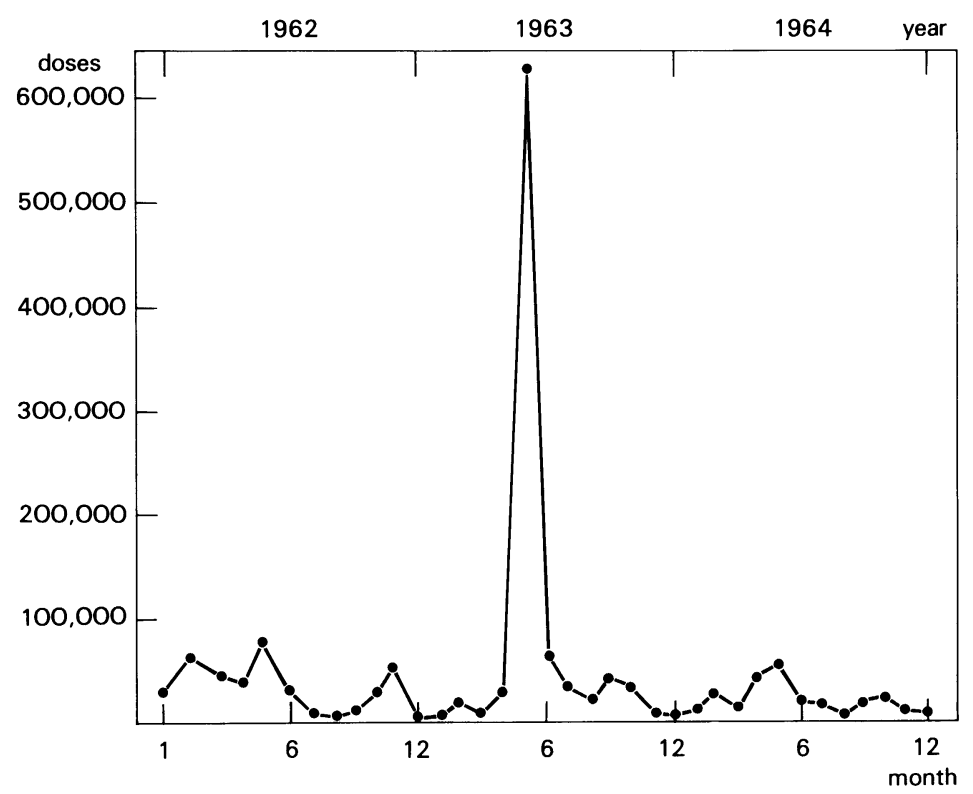

Figure 11. Timing of smallpox vaccination in 1963 according to the delivery figures of the vaccine. After Saxén et al. (1968).

statistical evaluation of the power of our detection method. Leaving the details of this published analysis aside, the unexpected conclusion was reached that in this seemingly ideal situation for an epidemiologic study an effect would have been detected only if every second vaccinated mother had lost her fetus. The lesson of this odyssey is that too often negative results are reported without testing the power of the material or without considering the confidence intervals of the estimated magnitude of an association.

\section{LIMITATIONS AND PITFALLS OF EPIDEMIOLOGIC STUDIES}

As indicated at various places in the above discussion, epidemiologic study methods and various surveillance programs in teratology have definite limitations and inherent error sources, both known and unknown. Everyone involved in such investigations should be aware of them, even if they cannot always be avoided and eliminated. During the study program summarized above, efforts were made to uncover such problem areas, to analyze their effect, and to eliminate them either by a proper design of investigation or by critical treatment of the data (Saxén, $1974,1975,1980)$. In the following some of these efforts will be described. 


\subsection{Definitions}

The terminology of teratology is still confusing and the definitions of congenital malformations (defects, abnormalities, anomalies) vary greatly. The main consequence is the difficulty of comparing different reports on the incidence of these defects in different materials. For this reason many international collaborative projects have been unfruitful, as the reported incidence figures for malformations have varied greatly (Stevenson et al., 1966).

The definition of malformations may also affect the selection of cases to be analyzed, as well as the results, as shown in the following example: in the thorough follow-up study by Klemetti (1978) all deviations from normal were recorded in detail and divided into three categories: (I) actual structural malformations, (II) congenital defects, including those of group I and all functional defects plus those whose inclusion as malformations is questionable (e.g., pyloric stenosis, dislocation of the hip, malposition of the feet, etc.), and (III) "all defects," including those of groups I and II and all minor abnormalities of apparent prenatal origin.

Associations of the risk indicators listed in Table I with these three groups of defects were then analyzed, and some of these are presented in Table XII. One can observe how the associations detected between the risk indicators and group I defects gradually become diluted when the definition "malformation" is broadened. In fact, the significant findings in group I are practically lost when functional defects and minor anomalies are included. In case of nonteratogenic variables, such as vitamins, the exposure rate was the same in the three groups.

The above "dilution effect" apparently includes several elements: the real structural malformations reflect impaired organogenesis, and their sensitive period

Table XII. Percentage of Certain Risk Indicators in Three Different Categories of Congenital Defects

\begin{tabular}{lcccc}
\hline & \multicolumn{3}{c}{ Defect $^{b}$} & \\
\cline { 2 - 4 } & I & II & III & Controls \\
& $(93)$ & $(197)$ & $(334)$ & $(2579)$ \\
\hline Unmarried mother & $4.3^{c}$ & 3.1 & 2.4 & 1.4 \\
Low placental weight & $13.5^{e}$ & $8.9^{d}$ & 6.0 & 3.5 \\
Low birth weight & $16.1^{e}$ & $9.7^{e}$ & $8.4^{e}$ & 3.3 \\
Maternal influenza & $11.8^{c}$ & 10.7 & 8.7 & 6.0 \\
Intake of sedatives & $6.5^{c}$ & 4.6 & 3.3 & 1.8 \\
\hline
\end{tabular}

${ }^{a}$ Klemetti (1977).

${ }^{b}$ I, Structural malformations. II, All congenital defects. III, All congenital (?) disorders.

${ }^{c} P<0.05$.

${ }^{d} P<0.01$.

${ }^{e} P<0.001$. 
is roughly known (first trimester), whereas the possible insult leading to other defects may have occurred at any stage of intrauterine development. Second, the larger groups of "defects" and "anomalies" may well include disorders in which exogenous agents play no causative role. The lesson from this analysis is that, whenever possible, the study material should not only be clearly defined but also restricted to definite "malformations" or, preferably, to certain indicator defects as already discussed.

\subsection{Maternal Memory Bias}

Most case-control studies base their data mainly or exclusively on postdelivery collection of information, usually by maternal interviews. It is therefore to be expected that this information is affected by limitations of memory and that the mother may not accurately recall details of her early pregnancy (type of drug, time of minor complications, period of fever, etc.), perhaps leading to misclassification. Moreover, memory might not only be limited, but might be biased by the outcome of the pregnancy; mothers of defective children may more actively ponder events during the pregnancy that could have led to the mishap. Thus far such biases have not been conclusively demonstrated, but suggestive data have been reported. Polydactyly is generally considered to be predominantly hereditary, and the same conclusion was reached by us on the basis of the results and estimates presented in Figs. 8 and 9. It is therefore unexpected to find a significant association between this disorder and a maternal report of salicylate intake during the first trimester of pregnancy (Granroth, 1978).

Maternal memory was directly tested in the prospective study mentioned above (Klemetti, 1966; Klemetti and Saxén, 1967). More than 3500 mothers were interviewed during their fifth month of pregnancy, and among other variables, drug intake and pregnancy complications during early gestation were carefully recorded. After delivery the same interviewer (who, however, was not in possession of the earlier collected information) reinterviewed those 203 mothers who had given birth to a stillborn or defective child and their matched-pair controls. The two sets of answers were then compared and poor repeatability was recorded; considering all variables tested, only $25 \%$ of the data collected during pregnancy appeared in an identical form in the postdelivery interview. Correspondingly, 65\% of the positive replies in the "retrospective" inquiry were missing in the replies obtained during the fifth month of pregnancy. An example of this analysis is given in Table XIII, which also demonstrates that no selective memory bias could be shown in this restricted material: the analysis showed that maternal memory seemed to be equally poor among both study and control mothers.

The only way to avoid both memory misclassification and selective memory bias would be to conduct laborious prospective studies on large maternal cohorts (Villumsen, 1970; Heinonen et al., 1977; Aarskog, 1979) or to collect actually documented information (results of laboratory tests, drug prescriptions, etc.). Con- 
Table XIII. Number of Mothers Giving Positive Replies in Different Groups in the Prospective Study and Corresponding Number of Identical Replies in Retrospective Interviews of the Same Mothers ${ }^{a}$

\begin{tabular}{lcc}
\hline & $\begin{array}{c}\text { Normal child } \\
(203 \text { mothers })\end{array}$ & $\begin{array}{c}\text { Deaths and } \\
\text { malformations } \\
\text { (203 mothers) }\end{array}$ \\
\hline $\begin{array}{l}\text { Diseases reported in the prospective } \\
\text { study }\end{array}$ & 34 & 43 \\
$\begin{array}{l}\text { Identical replies in the retrospective } \\
\text { study }\end{array}$ & 1 & 7 \\
$\begin{array}{l}\text { Additional retrospective information } \\
\text { ("false-positive?") }\end{array}$ & 11 & 15 \\
$\begin{array}{l}\text { Positive drug consumption in the } \\
\text { prospective study }\end{array}$ & 182 & 187 \\
$\begin{array}{l}\text { Identical replies in the retrospective } \\
\text { study }\end{array}$ & 33 & 23 \\
$\begin{array}{l}\text { Additional retrospective information } \\
\text { ("false-positive?") }\end{array}$ & 41 & 57 \\
\hline
\end{tabular}

${ }^{a}$ Klemetti and Saxén (1967).

cerning the case-control study program of the FRCM, much of the information was collected this way by the Maternity Welfare Centers during the mothers' repeated antenatal visits. However, when such information is supplemented by data from postdelivery interviews a maternal memory bias must always be kept in mind.

Assuming that there is a true maternal memory bias, it can sometimes be eliminated by proper design of the study. One such effort was made in analyzing the association between maternal influenza during early pregnancy and drug intake in the study and control mothers. Eighty mothers who reported influenza during early pregnancy were found from the files of the FRCM for CNS defects, and the risk ratios of their drug consumption were determined by a comparison with their matched pairs. Another 80 mothers were then singled out from the files of similarly defective children, and the risk ratios were again calculated by using the paired controls (Karkinen-Jääskeläinen and Saxén, 1974). The results illustrated in Table XIV show the expected linkage between influenza ("flu") and medication, but also an increased drug consumption in the noninfluenza group of mothers of children with identical defects.

\subsection{Confounding Factors}

The above example brings us to an important difficulty of most epidemiologic studies, whether a cohort study or a case-control investigation. That is the confounder bias caused by factors linked to both the outcome and the study variable. 


\section{Table XIV. Drug Intake during the First Trimester of Two Maternal Groups of Children with CNS Defects and Its Association with Influenza ${ }^{a}$}

\begin{tabular}{lcc}
\hline & \multicolumn{2}{c}{ Odds ratio $^{b}$} \\
\cline { 2 - 3 } & $\begin{array}{c}\text { Mothers with a positive } \\
\text { history of influenza }\end{array}$ & $\begin{array}{c}\text { Mothers with a negative } \\
\text { history of influenza }\end{array}$ \\
\hline All drugs & 3.0 & 2.5 \\
Salicylates & 13.5 & 2.5 \\
Undefined analgesics & 7.0 & 2.0 \\
Sedatives & 2.1 & 1.0 \\
Others & 4.7 & 3.0 \\
\hline
\end{tabular}

${ }^{a}$ Karkinen-Jääskeläinen and Saxén (1974).

${ }^{b}$ Odds ratios calculated from the matched-pair control mothers.

These can be potentially teratogenic, but also quite harmless. "Pure" study situations are rare, but we may have dealt here with two of thern: the sauna bath of young healthy women should not be linked to any additional factors, and, similarly, smallpox vaccination might represent an unconfounded study situation. To illustrate a confounded study situation, influenza and its medication can be mentioned again.

In 1957 an influenza pandemic was recorded (Asian influenza) and an attack rate of $30 \%$ was estimated in the city of Helsinki. The date and duration of this epidemic were evaluated from the continuous register of absenteeism of a large cohort of city employees. The epidemic lasted about a month and was dated October-November 1957 (Fig. 12A). Analysis of 6000 children born to this cohort was made subsequently, and a significant elevation in the risk of developing a CNS defect was observed in children who during the epidemic had been in their sensitive period (first 3 months) of intrauterine life (Saxén et al., 1960). To evaluate the association of the influenza epidemic with the consumption of drugs in the cohort, sales figures for drugs were collected from the main pharmacists in the city of Helsinki. The expected sales figures for 1957 were calculated from the figures of the "normal" years 1956, 1958, and 1959 (Fig. 12B). A remarkable peak in sales figures was found to have occurred in October-November 1957, i.e., during the epidemic. It was concluded that the association between this time period and the increased risk for CNS defects could well be due to the uptake of one or several drugs rather than to the viral infection (Hakosalo and Saxén, 1971).

If confounding factors cannot be eliminated by the design of the study, proper multivariate analyses might prove helpful, especially in case-control studies. The mathematical methods for such analyses fall outside the scope of this survey, but an example is given in Table XV, again dealing with influenza and its medication 

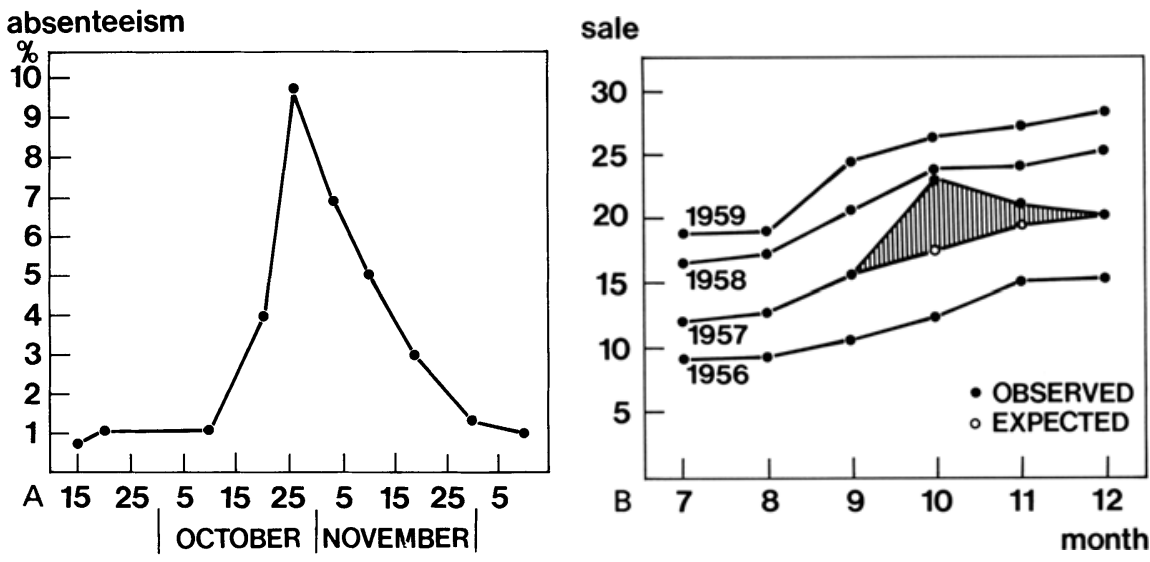

Figure 12. Timing of the influenza epidemic in 1957 according to absenteeism figures (A), and estimation of the parallel changes in drug consumption according to overall sales figures for drugs (B). After Hakosalo and Saxén (1971).

Table XV. Influence of Confounders on Associations of Maternal Influenza and Salicylate Consumption with Defects of the CNS in the Linear Logistic Regression Model $^{a}$

\begin{tabular}{|c|c|c|c|c|}
\hline Exposure factor & $\begin{array}{c}\text { Number of } \\
\text { discordant pairs }\end{array}$ & $\begin{array}{l}\text { Crude } \\
\text { odds ratio }\end{array}$ & $\begin{array}{l}\text { Adjusted } \\
\text { odds ratio }\end{array}$ & $\begin{array}{l}\text { Confounders included in } \\
\text { reanalysis }\end{array}$ \\
\hline Influenza & 227 & $1.9^{b}$ & $1.5^{c}$ & $\begin{array}{l}\text { Salicylates } \\
\text { Penicillin } \\
\text { Cough medicines } \\
\text { Sulfonamides } \\
\text { Psychopharmacologic } \\
\quad \text { agents }\end{array}$ \\
\hline Influenza, first trimester & 39 & $2.5^{b}$ & 1.7 & Salicylates \\
\hline Salicylates & 307 & $2.0^{b}$ & $2.0^{b}$ & $\begin{array}{l}\text { Influenza } \\
\text { Sympathomimetics } \\
\text { Antineurotics } \\
\text { Pyrazolones } \\
\text { Antibiotics } \\
\text { Maternal age > } 34\end{array}$ \\
\hline Salicylates, first trimester & 60 & $4.3^{b}$ & $4.0^{b}$ & Influenza \\
\hline Influenza and salicylates & 152 & $2.7^{b}$ & $2.7^{b}$ & $\begin{array}{l}\text { Sympathomimetics } \\
\text { Cough medicines } \\
\text { Antibiotics } \\
\text { Pyrazolones }\end{array}$ \\
\hline
\end{tabular}

${ }^{a}$ Granroth et al. (1978).

${ }^{b} P<0.001$.

${ }^{c} P<0.01$. 


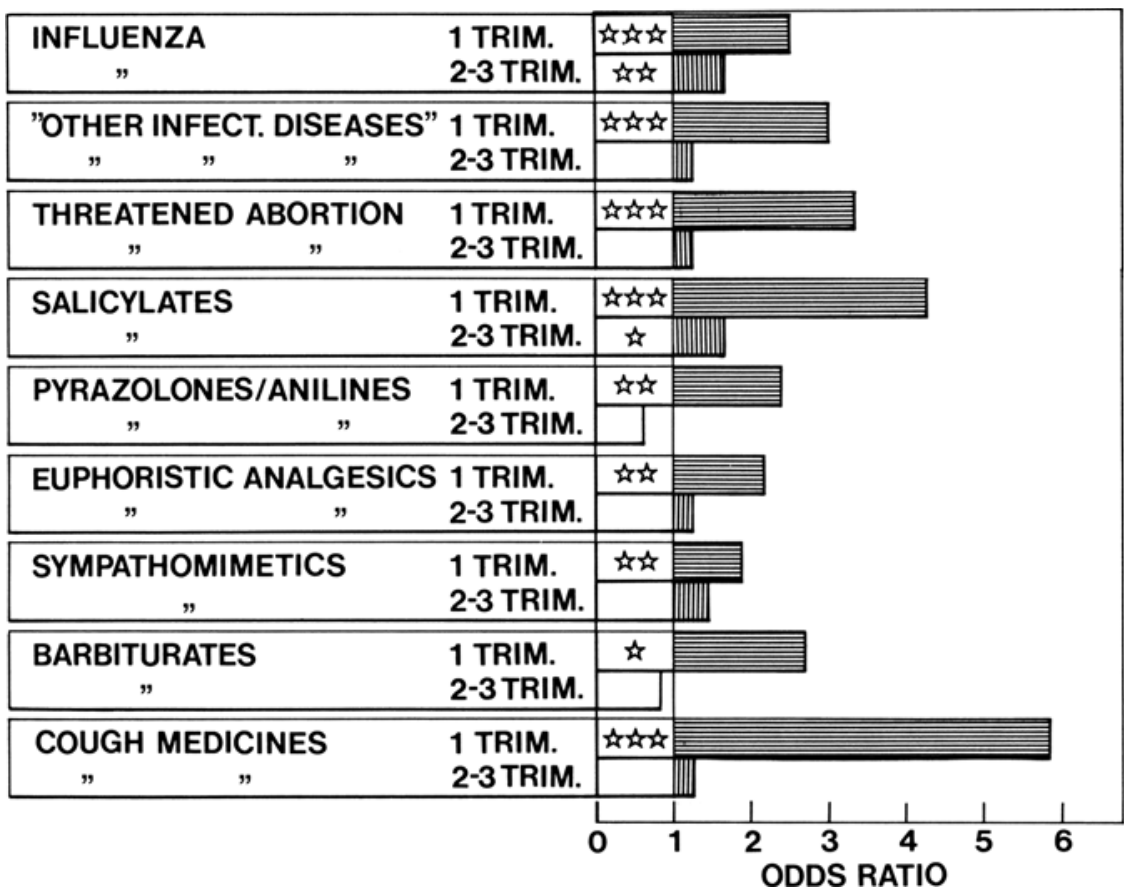

Figure 13. Risk ratios of CNS defects for children whose mothers reported a disease or consumption of drugs during pregnancy. Given as unit risk for children of the matched-pair mothers. The variables are recorded separately for the first trimester and for the rest of the pregnancy ( $r, P<0.05$; 计, $P<0.01 ;$. $P<001)$. After Granroth (1978).

in a group of mothers of children with CNS defects. The analysis shows that the confounders might not necessarily explain the observed associations. A similar analysis on oral clefts demonstrated that, in contrast, the observed effect of fever could be explained by confounding medication (Saxén, 1975c).

\subsection{Chance Correlations}

The risk of chance correlations always exists in screening programs without a definite hypothesis, when a great number of variables are compared with several groups of defects. Naturally, determination of statistical significance indicates the magnitude of this risk in a single association, but it is infrequently corrected for multiple testing situation, and even if corrected it cannot pinpoint the "nonsense" findings. No doubt, many such chance correlations have found their way into the teratologic literature, from which they become removed only slowly, when subsequent studies fail to confirm them. In a certain sense teratologic studies might 


\begin{tabular}{|c|c|c|}
\hline & Northern Carelia & Rest of Finland \\
\hline Incidence of anencephaly & $0.61 / 1000(P<0.05)$ & $0.31 / 1000$ \\
\hline Mothers over 40 years & $4.2 \%(P<0.001)$ & $2.7 \%$ \\
\hline
\end{tabular}

${ }^{a}$ Granroth et al. (1977).

be less vulnerable than many other epidemiologic approaches: correlations of insults beyond the sensitive period can be excluded, and for most malformations correlations only during the first trimester should be considered, as in the findings illustrated in Fig. 13.

\subsection{Controls}

In case-control investigations proper controls are as important as the study mothers. Adequate matching is not necessarily difficult, but in screening programs without hypotheses it may cause trouble. Variables to be studied cannot be used as matching criteria (e.g., maternal age). Hence, in the matched-pair screening program described here the designers were left with two variables to be matched, the domicile of the mother and the season of birth of the child. An example of the effect of this matching according to area is given below.

A case-control approach to studying the significance of maternal age in the development of CNS defects was made. Contrary to previous findings, and those illustrated in Fig. 7, no significant differences were found, but the confusing observations was made that in both the case group and the controls older mothers were overrepresented. The explanation seems to lie in the matching done according to the maternal domicile; as shown in Fig. 6, the incidence of anencephaly was highest in the eastern part of the country, and here the family size is also known to be large. The statistics show that the mean maternal age is higher in that part of the country, and in particular the proportion of mothers in the oldest age group is high (Table XVI). Thus the area-matched control mothers of the anencephaly cases also deviated from the normal age distribution, and the age difference between the cases and the controls disappeared. Because in this instance area was a confounding factor in studying the effect of age, matching controlled it properly.

\section{CONCLUDING REMARKS}

As with previous efforts, the rather extensive screening program and related special studies described here failed to demonstrate single teratogens. There were, 
however, achievements that might be considered worth the effort: several factors and conditions earlier suggested to be harmful for the embryo were excluded with reasonable level of confidence, including sauna, coffee, and oral contraceptives. In addition, indicators repeatedly shown to be associated with an elevated risk for the defects studied might become useful when delineating high-risk groups of mothers for prenatal diagnostics and intense fetal surveillance. Such factors, common to most types of malformations, were analyzed here: increased maternal age, previous stillbirths and defective children, threatened abortion, heavy medication during early pregnancy (salicylates), and febrile conditions during that period ("influenza"). Finally, such nation-wide programs may favorably influence the general attitude toward the important problem of crippled children and the prevention of their birth. Additional motivations for epidemiologic studies in a small country are the many advantages of a small, stable, ethnically uniform, and cooperative population. These advantages should be utilized, especially if resources for major experimental programs are restricted.

AcKnowledgments. Most of the analytical work summarized in this survey was performed by my postgraduate students Timo Aro, Gustaf Granroth, Jukka Hakosalo, Peter Holmberg, Anneli Klemetti, and Irma Thesleff (Saxén). It has been a privilege to collaborate with these devoted colleagues. The author greatly appreciates the valuable comments of Prof. Olli P. Heinonen during the preparation of the manuscript.

\section{REFERENCES}

Aarskog, D. 1979. Maternal progestins as a possible cause of hypospadias. N. Engl. J. Med. 300:7578.

Aro, T., Heinonen, O. P., and Saxén, L. 1982. Incidence and secular trends of congenital limb defects in Finland. Int. J. Epidemiol. 11:239-244.

Aro, T., Heinonen, O. P., and Saxén, L. 1983. Risk indicators of reduction limb defects. J. Epidemiol. Community Health (in press).

Borlée, I., Lechat, M. F., Bouckaert, A., and Misson, C. 1978. Le café, facteur de risque pendant la grossesse? Louvain Med. 97:279-284.

Carr, D. H. 1970. Chromosome studies in selected spontaneous abortions. I. Conceptions after oral contraceptives. Can. Med. Assoc. J. 103:343-348.

Central Statistical Office of Finland. 1981. Statistical Yearbook of Finland 1980. Valtion painatuseskus, Helsinki.

Coffey, V. P., and Jessop, W. J. E. 1959. Maternal influenza and congenital deformities. A prospective study. Lancet 2:935-938.

Coffee, V. P., and Jessop, W. J. E. 1963. Maternal influenza and congenital deformities. A followup study. Lancet 1:748-751.

Fedrick, J. 1976. Anencephalus in Scotland, 1961-72. Br. J. Prev. Soc. Med. 30:132-137.

Fraser, F. C. 1964. Experimental teratogenesis in relation to congenital malformations in man, in: 
Second International Conference on Congenital Malformations, M. Fishbein, ed. International Medical Congress, New York, pp. 277-287.

Fraser, F. C. 1971. The epidemiology of common major malformations as related to environmental monitoring, in: Monitoring, Birth Defects and Environment, E. B. Hook, D. T. Janerich, and I. H. Porter, eds. Academic, New York, pp. 85-96.

Granroth, G. 1978. Defects of the central nervous system in Finland: III. Diseases and drugs in pregnancy. Early Hum. Dev. 2:147-162.

Granroth, G., Hakama, M., and Saxén, L. 1977. Defects of the central nervous system in Finland: I. Variations in time and space, sex distribution, and parental age. Br. J. Prev. Soc. Med. 31:164-170.

Granroth, G., Haapakoski, J., and Saxén, L. 1978. Defects of the central nervous system in Finland: V. Multivariate analysis of risk indicators. Int. J. Epidemiol. 7:301-308.

Green, D. M., Reid, S. M., and Rhaney, K. 1966. Generalized vaccinia in the human foetus. Lancet 1:1296-1298.

Hakosalo, J. K. 1973. Cumulative detection rates of congenital malformations in a ten-year followup study. Acta Pathol. Microbiol. Scand. A Suppl. 242:1-59.

Hakosalo, J., and Saxén, L. 1971. Influenza epidemic and congenital defects. Lancet 2:1346-1347.

Hämäläinen, T., Öhrnberg, R., and Saxén, L. 1970. Maternal age and congenital defects (in Finnish with English summary). Duodecim 86:719-729.

Hardy, J. M. B., Azarowicz, E. N., Mannini, A., Medearis, D. N., and Cooke, R. E. 1961. The effect of Asian influenza on the outcome of pregnancy, Baltimore 1957-58. Am. J. Public Health 51:1182-1188.

Hay, S., and Barbano, H. 1972. Independent effects of maternal age and birth order on the incidence of selected congenital malformations. Teratology 6:271-279.

Heinonen, O. P., Slone, D., and Shapiro, S. 1977. Birth Defects and Drugs in Pregnancy. Publishing Sciences Group, Littleton, Massachusetts.

Hemminki, K., Mutanen, P., Luoma, K., and Saloniemi, I. 1980. Congenital malformations by the parental occupation in Finland. Int. Arch. Occup. Environ. Health 46:93-98.

Hemminki, K., Mutanen, P., Saloniemi, I., and Luoma, K. 1981. Congenital malformations and maternal occupation in Finland: multivariate analysis. J. Epidemiol. Community Health 1:510.

Hemminki, K., Saloniemi, I., Kyyrönen, P., and Kekomäki, M. 1982. Gastroschisis and omphalocele in Finland in the 1970's: prevalence at birth and its correlates. J. Epidemiol. Community Health 36:289-293.

Hirvensalo, M., and Hjelt, L. 1963. The incidence of congenital malformations in a Finnish maternity hospital (in Finnish with English summary). Duodecim 79:798-803.

Holmberg, P. C. 1979. Central-nervous-system defects in children born to mothers exposed to organic solvents during pregnancy. Lancet 2:177-179.

Holmberg, P. C., and Kurppa, K. 1982. An epidemiologic approach to the study of possible teratogenic effects of chemical and physical environments. Scand. J. Work Environ. Health 8(Suppl. 1):89-91.

Idänpään-Heikkilä, J., and Saxén, L. 1973. Possible teratogenicity of combination imipramine-antihistamine. Lancet 2:282-284.

Karkinen-Jääskeläinen, M., and Saxén, L. 1974. Maternal influenza, drug consumption, and congenital defects of the central nervous system. Am. J. Obstet. Gynecol. 118:815-818.

Klemetti, A. 1966. Relationship of selected environmental factors to pregnancy outcome and congenital malformations. Ann. Paediatr. Fenn. 12(Suppl. 26):1-71.

Klemetti, A. 1977. Definition of congenital malformations and detection of associations with maternal factors. Early Hum. Dev. 1:117-123.

Klemetti, A. 1978. Congenital defects in a cohort followed for seven years. Acta Paediatr. Scand. 67:601-605. 
Klemetti, A., and Saxén, L. 1967. Prospective versus retrospective approach in the search for environmental causes of malformations. Am. J. Public Health 57:2071-2075.

Klemetti, A., and Saxén, L. 1970. The Finnish Register of Congenital Malformations. Organization and six years of experience. Health Ser. Res. Nat. Board Health Finland 9:1-30.

Koskimies, O., Lapinleimu, K., and Saxén, L. 1978. Infections and other maternal factors as risk indicators for congenital malformations: a case-control study with paired serum samples. Pediatrics 61:832-837.

Kurppa, K., Holmberg, P. C., Kuosma, E., and Saxén, L. 1982. Coffee consumption during pregnancy. N. Engl. J. Med. 306:1548.

Kurppa, K., Ojajärvi, J., Hernberg, S., Holmberg, P. C., Rantala, K., Riala, R., and Nurminen, T. 1983. Congenital malformations and occupational exposure to disinfectants. Scand. J. Work Environ. Health 9(1):(in press).

Lapinleimu, K., Koskimies, O., Cantell, K., and Saxén, L. 1972. Viral antibodies in mothers of defective children. Teratology 5:345-351.

Lapinleimu, K., Koskimies, O., Cantell, K., and Saxén, L. 1974. Association between maternal herpes-virus infections and congenital malformations. Lancet 1:1127-1129.

Layde, P. M., Edmonds, L. D., and Erickson, J. D. 1980. Maternal fever and neural tube defects. Teratology 21:105-108.

Leck, I. 1963. Incidence of malformations following influenza epidemics. Br. J. Prev. Soc. Med. 17:70-80.

Linn, S., Schoenbaum, S. C., Monson, R. R., Rosner, B., Stubblefield, P. G., and Ryan, K. J. 1982. No association between coffee consumption and adverse outcomes of pregnancy. $N$. Engl. J. Med. 3:141-145.

Mackeprang, M., and Hay, S. 1972. Credibility of reporting of malformations in birth certificates. J. Am. Med. Assoc. 222:90.

McBride, W. G. 1972. Limb deformities associated with iminodibenzyl hydrochloride. Med. J. Aust. 1:492.

McDonald, A. D. 1961. Maternal health in early pregnancy and congenital defect. Final report in a prospective inquiry. Br. J. Prev. Soc. Med. 15:154-166.

Mellin, G. W. 1963. The frequency of birth defects in: Birth Defects, M. Fishbein, ed. Lippincott, Philadelphia, pp. 1-17.

Miller, J. B. 1975. Some epidemiological aspects of teratogen detection. Mutat. Res. 33:45-54.

Miller, P., Smith, D. W., and Shepard, T. H. 1978. Maternal hyperthermia as a possible cause of anencephaly. Lancet 1:519-521.

Morris, M. B., and Weinstein, L. 1981. Caffeine and the fetus: is trouble brewing? Am. J. Obstet. Gynecol. 140:607-610.

National Board of Health. 1982. Health Services. Yearbook 1979-1980. Official Statistics of Finland, Volume XI. Valtion painatuskeskus, Helsinki, p. 77.

Neel, J. V. 1958. A study of major congenital defects in Japanese infants. Am. J. Hum. Genet. 10:398-445.

Nishimura, H., Takano, K., Tanimura, T., Yasuda, M., and Uchida, T. 1966. High incidence of several malformations in the early human embryos as compared with infants. Biol. Neonate 10:93-107.

Nowack, E. 1965. Die sensible Phase bei der Thalidomid-Embryopathie. Humangenetik 1:516-536.

Peterson, W. F. 1969. Pregnancy following oral contraceptive therapy. Obstet. Gynecol. 34:363367.

Pitkänen, H. 1964. Maternity welfare in Finland, in: Public Health Medical Care and the Medical Profession in Finland. Finnish Medical Association, Helsinki, pp. 1-8.

Poland, B. J., and Ash, K. A. 1973. The influence of recent use of an oral contraceptive on early intrauterine development. Am. J. Obstet. Gynecol. 116:1138-1142.

Rapola, J., Saxén, L., and Granroth, G. 1978. Anencephaly and the sauna. Lancet 2:1162. 
Record, R. G. 1961. Anencephalus in Scotland. Br. J. Prev. Soc. Med. 15:93-105.

Renwick, J. H. 1972. Hypothesis: anencephaly and spina bifida are usually preventable by avoidance of a specific but unidentified substance present in certain potato tubers. Br. J. Prev. Soc. Med. 26:67-88.

Renwick, J. H. 1973. Prevention of anencephaly and spina bifida in man. Teratology 8:321-323.

Rintala, A., and Stegars, T. 1982. Increasing incidence of clefts in Finland: reliability of hospital records and central Register of Malformations. Scand. J. Plast. Reconstr. Surg. 16:35-40.

Robinson, S. C. 1971. Pregnancy outcome following oral contraceptives. Am. J. Obstet. Gynecol. 109:354-358.

Rosenberg, L., Mitchell, A. A., Shapiro, S., and Slone, D. 1982. Selected birth defects in relation to caffeine-containing beverages. J. Am. Med. Assoc. 10:1429-1432.

Royal College of General Practitioners. 1976. Oral contraception study. The outcome of pregnancy in former oral contraceptive users. Br. J. Obstet. Gynaecol. 83:606-616.

Rumeau-Rouquette, C., Goujard, J., and Etienne, C. 1971. Relation entre les métrorragies du début de la grossesse et les malformations congénitales. Résultats d'une enquête prospective portant sur 9525 grossesses. Gynecol. Obstet. 70:557-562.

Safra, M. J., and Oakley, G. P. 1975. Association between cleft lip with or without cleft palate and prenatal exposure to diazepam. Lancet 2:478-480.

Savolainen, E., Saksela, E., and Saxén, L. 1981. Teratogenic hazards of oral contraceptives analyzed in a national malformation register. Am. J. Obstet. Gynecol. 140:521-524.

Saxén, I. 1975a. Associations between drugs taken during pregnancy and oral clefts. Int. J. Epidemiol. 4:37-44.

Saxén, I. 1975b. Epidemiology of cleft lip and palate: an attempt to rule out chance correlations. $\mathrm{Br}$. J. Prev. Soc. Med. 29:103-110.

Saxén, I. 1975c. The association between maternal influenza, drug consumption and oral clefts. Acta Odontol. Scand. 33:259-267.

Saxén, I., and Lahti, A. 1974. Cleft lip and palate in Finland: incidence, secular, seasonal, geographical variations. Teratology 9:217-224.

Saxén, I., and Saxén, L. 1975. Association between maternal intake of diazepam and oral clefts. Lancet 2:498.

Saxén, L. 1974. Population surveillance for birth defects, in: Birth Defects, A. G. Motulsky and W. Lenz, eds. Excerpta Medica, Amsterdam, pp. 177-186.

Saxén, L. 1975. Newborn monitoring, in: Methods for Detection of Environmental Agents That Produce Congenital Defects, T. H. Shepard, J. R. Miller, and M. Marois, eds. North-Holland, Amsterdam, pp. 205-220.

Saxén, L. 1977a. Drugs and teratogenesis, in: Epidemiological Evaluation of Drugs, F. Colombo, S. Shapiro, D. Slone, and G. Tognono, eds. Elsevier/North Holland, Amsterdam, pp. 267-276.

Saxén, L. 1977b. Il registro delle malformazioni in Finlandia (1963-1976). Prospett. Pediatr. 27:217-224.

Saxén, L. 1980. Epidemiological studies for detection of teratogens, in: Proceedings of a Workshop on Methodology for Assessing Reproductive Hazards in the Workplace. U. S. Department of Health and Human Services (NIOSH) Publication No. 81-100, Washington, D.C., pp. 357376.

Saxén, L. 1983. The prediction and detection of teratogenicity, in: Occupational Hazards and Reproduction, K. Hemminki, M. Sorsa, and H. Vainio, eds. Hemisphere, Washington, D.C. (in press).

Saxén, L., and Härö, S. 1964. Malformations of newborns in Finland (in Finnish with English summary and table legends). Duodecim 80:257-263.

Saxén, L., and Klemetti, A. 1974. The Finnish Register of Congenital Malformations. Acta Univ. Caroliensis Med. LVI-LVII:23-30.

Saxén, L., and Rapola, J. 1969. Congenital Defects. Holt, Rinehart and Winston, New York. 
Saxén, L., Hjelt, L., Sjöstedt, J., Hakosalo, J., and Hakosalo, H. 1960. Asian influenza during pregnancy and congenital malformations. Acta Pathol. Microbiol. Scand. 49:114-126.

Saxén, L., Cantell, K., and Hakama, M. 1968. Relation between smallpox vaccination and outcome of pregnancy. Am. J. Public Health 58:1910-1921.

Saxén, L., Klemetti, A., and Härö, S. A. 1974. A matched-pair register for studies of selected congenital defects. Am. J. Epidemiol. 100:297-306.

Saxén, L., Holmberg, P. C., Nurminen, M., and Kuosma, E. 1982. Sauna and congenital defects. Teratology 25:309-313.

Smith, D. W., Clarren, S. K., and Sedwick Harvey, M. A. 1978. Hyperthermia as a possible teratogenic agent. J. Paediatr. 92:878-883.

Smithells, R. W. 1976. Environmental teratogens of man. Br. Med. Bull. 32:27-33.

Stevenson, A. C., Johnston, H. A., Stewart, M. I. P., and Golding, D. R. 1966. Congenital malformations. A report of a study of series of consecutive births in 24 centers. Bull. WHO 34(Suppl.):1-127.

Teppo, L., Pukkala, E., Hakama, M., Hakulinen, T., Herva, A., and Saxén, E. 1980. Way of life and cancer incidence in Finland. Scand. J. Soc. Med. Suppl. 19.

Timonen, S., Malm, E., Lokki, O., and Vara, P. 1968. Factors influencing perinatal mortality and malformations in the newborn. Ann. Paediat. Fenn. 14:35-42.

Uhari, M., Mustonen, A., and Kouvalainen, K. 1979. Sauna habits of Finnish women during pregnancy. Br. Med. J. 1:1216.

Villumsen, A. I. 1970. Environmental Factors in Congenital Malformations. A prospective study of 9006 human pregnancies. FADI Forlag, Copenhagen.

Weatherall, J. A. C. 1970. The detection of incidence of congenital malformations in the community. Proc. R. Soc. Med. 63:1251-1252.

Weathersbee, P. S., Olsen, L. K., and Lodge, J. R. 1977. Caffeine and pregnancy: a retrospective survey. Postgrad. Med. 62:64-69.

Wilson, J. G. 1973. Environment and Birth Defects. Academic, New York. 